\title{
Indications for referral and assessment in adultliver transplantation: a clinical guideline
}

\author{
J Devlin, J O’Grady
}

\subsection{Foreword}

This document, on the indications and referral of patients for liver transplantation, was commissioned by the British Society of Gastroenterology (BSG) as part of a wider initiative to develop guidelines for clinicians in several areas of clinical practice.

The role of transplantation in end stage liver disease has reached a period of stability following a phase of rapid development over the past two decades. Emerging from an experimental high risk procedure to one where survival and rehabilitation is anticipated, it is appropriate to review the present evidence and synthesise this into a framework document for referring clinicians.

Guidelines are not rigid protocols and they should not be construed as interfering with local clinical judgement. Hence, they do not represent a directive of prescribed routes but a basis upon which clinicians can consider the option of transplantation more clearly.

\subsection{Introduction and objectives}

These guidelines tackle the inter-related topics of the indications and optimal referral practice for liver transplantation. Between 1980 and 1990, after several clinical advances, liver transplantation became established as the preferred treatment in a range of acute and chronic end stage liver disorders. Patient survival rates have improved steadily $(\geqslant 90 \%$ survival at one year is now achievable in low risk elective recipients) with an accompanying rapid expansion in liver transplant services. Hence, a considerable wealth of experience is now available for review and from which recommendations on indications for transplantation and patient selection can be derived.

Optimising referral practice to tertiary centres for transplantation is also tackled and the importance of the clinical status of the patient at the time of transplantation on the subsequent outcome of the procedure is reviewed. Delays in referral and extended waiting times for transplantation can allow unfavourable complications of advanced liver disease to supervene thereby jeopardising the outcome.

Guidelines are proposed on the two core questions: (a) which categories of patients should be considered for transplantation and (b) when in the course of their illness should possible candidates be referred to specialist centres? In reaching conclusions, a systematic review of two principal issues is undertaken: (1) the natural history of advanced liver disorders and (2) how the lessons already learned on the outcome of transplantation are promoting a more refined selection of suitable candidates.
These guidelines only discuss the medical indications and although some of the ethical issues are highlighted, no attempt is made to make firm recommendations in these difficult areas.

\subsection{Formulation of guidelines}

A systematic review of the relevant literature and synthesis of available evidence with later phases of peer group appraisal and then expert review was performed. Draft proposals were amended at each stage. The strength of evidence used in these guidelines was that recommended by the north of England evidence based guidelines development project. ${ }^{1}$

\section{CATEGORIES OF EVIDENCE}

Ia Evidence obtained from meta-analysis of randomised controlled trials.

$\mathrm{Ib}$ Evidence obtained from at least one randomised trial.

IIa Evidence obtained from at least one well designed controlled study without randomisation.

$\mathrm{IIb}$ Evidence obtained from at least one other type of well designed quasi-experimental study.

III Evidence obtained from well designed non-experimental descriptive studies such as comparative studies, correlation studies and case studies.

IV Evidence obtained from expert committee reports or opinions or clinical experiences of respected authorities.

GRADING OF RECOMMENDATIONS

Recommendations are based upon the level of evidence presented in support and are graded accordingly.

A Requires at least one randomised controlled trial of good quality addressing the topic of recommendation.

B Requires the availability of clinical studies without randomisation on the topic of recommendation.

Abbreviations used in these guidelines: $\mathrm{AIH}$ autoimmune hepatitis; ALD, alcoholic liver disease; ALF, acute liver failure; BSG, British Society of Gastroenterology; HBsAg, hepatitis B surface antigen; EHE, epithelioid haemangioendothelioma; ELTR, European Liver Transplant Registry; FHF, fulminant hepatic failure; HAV, hepatitis A virus; HBV, hepatitis

B virus; $\mathrm{HCC}$, hepatocellular carcinoma; HCV, hepatitis $\mathrm{C}$ virus; HDV, hepatitis D virus; HBIG, hepatitis B immunoglobulin; INR, international normalised ratio; LOHF, late-onset hepatic failure; NANB, non A-non B; NSAID, non-steroidal anti-inflammatory drug; OLT, orthotopic liver transplant; PBC, primary biliary cirrhosis; PSC, primary sclerosing cholangitis; UKTSSA United Kingdom Transplant Support Service Authority; UNOS, United Network Organ Sharing. 
C Requires evidence from category IV in the absence of directly applicable clinical studies.

A feature of the development of clinical practice in the field of organ transplantation is the acceptance of this treatment modality as having clinical worth without the rigorous evaluation normally required for other therapies. Several logistic and ethical reasons explain this position which has also occurred in the development of liver transplantation. Hence, randomised trials (categories of evidence Ia and $\mathrm{Ib}$ ) are virtually unknown and accordingly a topic with a grade $\mathrm{A}$ recommendation is rarely achievable.

\subsection{Summary of recommendations}

GENERAL CONSIDERATIONS

- Potential transplant candidates should be assessed on the basis of:

(i) profile of complications;

(ii) calculated prognosis;

(iii) quality of life.

(Recommendation grade C.)

- Early referral of potential candidates to transplant programmes facilitates the timing and outcome of transplantation. (Recommendation grade $\mathrm{B}$.)

- Referral, and hence transplantation, should preferably occur before the development of malnutrition, hepatorenal failure, and an advanced UNOS score (see appendix I for the UNOS grading system). (Recommendation grade B.)

- Transplantation should not be discouraged in patients over 60 years of age. (Recommendation grade B.)

- The conditions listed in box 1 are absolute and relative (generally weighs heavily against transplantation) contraindications to liver transplantation. (Recommendation grade B.)

\section{Box 1 Absolute and relative contraindications to liver transplantation \\ ABSOLUTE CONTRAINDICATIONS \\ AIDS}

Extrahepatic malignancy ${ }^{\star}$

Advanced cardiopulmonary disease

Cholangiocarcinoma $†$

RELATIVE CONTRAINDICATIONS

HIV positivity

Age above 70 years

Significant sepsis outside the extrahepatic biliary tree

HBV DNA positivity

Active alcohol/substance misuse

Severe psychiatric disorder

Portal venous system thrombosis $₫$

Pulmonary hypertension』

^Haemangioendothelioma and neuroendocrine malignancy are an exception in some centres.

†Relative contraindication in some centres in conjunction with experimental approaches.

$\ddagger$ Most patients can be treated with antiviral therapy.

§Require assessment at a transplant centre.
ACUTE LIVER FAILURE

- In cases of paracetamol hepatotoxicity, the guidelines given in table 1 for referral to specialist centres are proposed. (Recommendation grade C.)

- Patients with non-paracetamol acute and subacute liver failure (defined by the presence of encephalopathy, including fulminant Wilson's disease) should be referred to a transplant centre. (Recommendation grade B.)

- Patients with non-paracetamol liver failure and a progressive coagulopathy, in the absence of encephalopathy, should be discussed with a transplant centre. (Recommendation grade C.)

CHOLESTATIC LIVER DISORDERS

Primary biliary cirrhosis

- Primary biliary cirrhosis (PBC) is an excellent indication for transplantation. (Recommendation grade A.)

- Prognostic and palliative indications are both justified. (Recommendation grade C.)

- Referral should be made once the serum bilirubin exceeds $100 \mu \mathrm{mol} / 1$ or significant impairment of liver function ensues. (Recommendation grade B.)

- Earlier referral is justified if symptoms or complications are prominent. (Recommendation grade C.)

Primary sclerosing cholangitis

- The optimal timing of transplantation in primary sclerosing cholangitis (PSC) has not been defined and hence early referral is recommended. (Recommendation grade B.)

- Stringent efforts to detect superadded cholangiocarcinoma are necessary but these are suboptimal and unreliable. (Recommendation grade B.)

- A Mayo model score of $\geqslant 5$ or a Child grade C score justifies referral for transplantation. (Recommendation grade B.)

\section{Autoimmune hepatitis}

- Transplantation is a viable option for autoimmune hepatitis (AIH). (Recommendation grade B.)

- Failure to achieve biochemical remission, shrinking liver volume, severe acute presentation and progressive decompensation in chronic cases are indications for transplant assessment. (Recommendation grade C.)

ALCOHOLIC LIVER DISEASE

- Reasons for the apparent low level of referral of patients with alcoholic liver disease (ALD) for transplantation need to be elucidated. (Recommendation grade C.)

Table 1 Guidelines for referral to specialist centres in cases of paracetamol hepatotoxicity

\begin{tabular}{|c|c|c|}
\hline Day 2 & Day 3 & Day 4 \\
\hline Arterial $\mathrm{pH}<7.30$ & Arterial $\mathrm{pH}<7.30$ & - \\
\hline INR $>3$ & INR $>4.5$ & Any rise in INR \\
\hline Encephalopathy & Encephalopathy & Encephalopathy \\
\hline $\begin{array}{l}\text { Creatinine } \\
\mu \mathrm{mol} / 1\end{array}$ & $\begin{array}{l}\text { Creatinine }>200 \\
\mu \mathrm{mol} / 1\end{array}$ & $\begin{array}{l}\text { Creatinine }>250 \\
\mu \mathrm{mol} / 1\end{array}$ \\
\hline
\end{tabular}

Day X, day after overdose; INR, international normalised ratio 
- Transplantation in selected patients with advanced ALD can improve outcome. (Recommendation grade A.)

- A six month period of supervised community abstinence is desirable but not mandatory. (Recommendation grade B.)

- Young patients on first medical presentation may not need to undergo the usual stringent evaluation if the illness is life threatening. (Recommendation grade C.)

- Psychosocial assessment should be performed by a multi-disciplinary transplant team. (Recommendation grade B.)

- Alcohol dependence should be differentiated from non-dependent misuse. (Recommendation grade B.)

- Exclusion of significant comorbid disease is an essential element of assessment. (Recommendation grade B.)

\section{CHRONIC HEPATITIS}

Hepatitis $B$

- Patients with end stage chronic hepatitis B virus (HBV) related liver disease must be HBV DNA negative before transplantation. (Recommendation grade B.) HBV DNA positivity is based on commercial non-PCR based assays.

- The majority of HBV DNA positive patients can be rendered HBV DNA negative with antiviral treatment and should not be excluded from assessment. (Recommendation grade B.)

- Long term passive immunisation with hepatitis B immunoglobulin is an effective strategy to prevent reinfection. (Recommendation grade A.)

- Precore mutant HBV or hepatitis D virus (HDV) co-infection are not contraindications to transplantation. (Recommendation grade $\mathrm{B}$.)

Hepatitis $C$

- Patients with end stage hepatitis C cirrhosis should be considered for transplantation. (Recommendation grade B.)

- Genotype and viral load should not influence transplant assessment. (Recommendation grade B.)

- Uncontrolled drug dependency is a relative contraindication to transplantation. (Recommendation grade C.)

- Alcohol misuse should be actively excluded in cases of hepatitis C. (Recommendation grade $\mathrm{B}$.)

- Haemophilia is not a contraindication to transplantation. (Recommendation grade C.)

LIVER MALIGNANCY

Hepatocellular carcinoma

- Transplantation is recommended for most small hepatocellular carcinomas (HCC) complicating cirrhosis. (Recommendation grade A.)

- Tumours $>5 \mathrm{~cm}$ or greater than three in number should only be assessed in conjunction with a novel management strategy. (Recommendation grade B.)
- Local or systemic extrahepatic HCC disease is an absolute contraindication to transplantation. (Recommendation grade A.)

- The fibrolamellar variant of HCC is not constrained by these size and volume criteria for transplantation. (Recommendation grade A.)

Cholangiocarcinoma

- Cholangiocarcinoma is not an indication for transplantation unless in conjunction with a novel management strategy. (Recommendation grade A.)

\section{Epithelioid haemangioendothelioma}

- Patients with epithelioid haemangioendothelioma (EHE) should be referred for expert histopathological and radiological opinion to exclude angiosarcoma. (Recommendation grade B.)

- Extrahepatic disease may not be a contraindication to transplantation in EHE, although this varies from centre to centre. (Recommendation grade B.)

\section{Metastatic liver tumours}

- Neuroendocrine tumours are the only metastatic liver tumours suitable for transplantation for palliation. (Recommendation grade A.)

- Extrahepatic metastatic disease from neuroendocrine tumours is a contraindication to transplantation. (Recommendation grade A.)

Others

- Budd-Chiari syndrome is optimally managed in a centre offering the four main therapeutic options of decompressive surgery, transplantation, TIPS, and radiological intervention. (Recommendation grade B.)

- Familial amyloid polyneuropathy should continue to be evaluated as an indication for transplantation with particular regard to the influence of genotypic and phenotypic variants and stage of disease on outcome. (Recommendation grade C.)

- Transplantation for genetic haemochromatosis is a viable option but should be considered a higher risk procedure than other elective indications. (Recommendation grade C.)

- Wilson's disease is a good indication for transplantation. (Recommendation grade B.)

\subsection{Background}

5.1 EPIDEMIOLOGY OF LIVER DISEASE

Data on the incidence, prevalence, morbidity, and mortality of liver disease in the United Kingdom are inexact and should be interpreted cautiously. Indeed, a need for a comprehensive and prospective study of the epidemiology of liver disease in the UK has been identified.

Over 3000 deaths from cirrhosis/chronic liver disease (ICD9 code 571) are reported in England and Wales every year with about 1200 attributed to alcohol related liver disease. ${ }^{2}$ These death certificate figures, which are increasing annually, may underestimate the true extent of liver related mortality by 


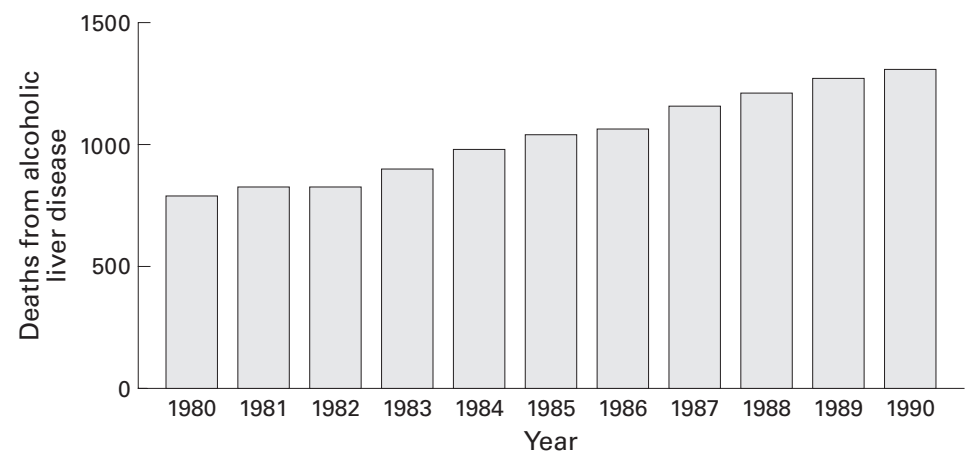

Figure 1 Reported mortality from alcohol related liver disease in the United Kingdom.

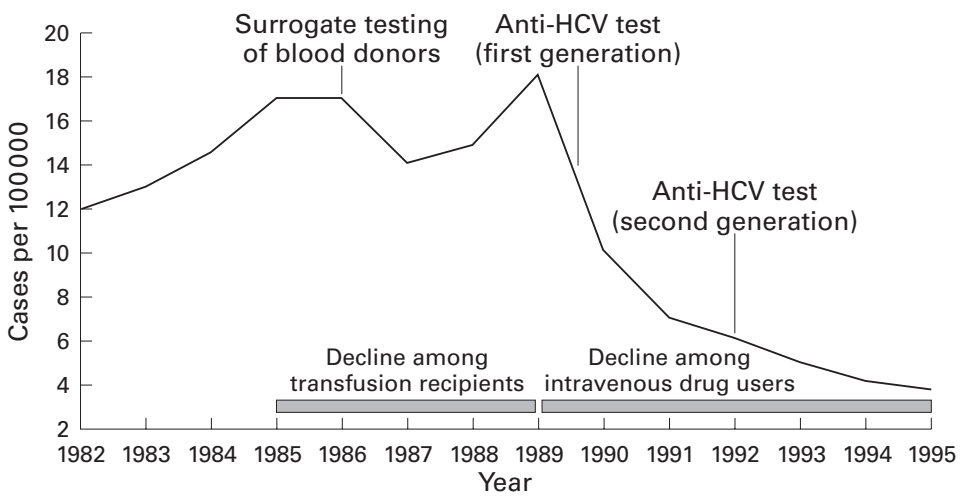

Figure 2 Rapid decline in de novo hepatitis C (HCV) infection (United States).

between $30 \%$ and $60 \% .^{3-5}$ In contrast to these figures, transplantation was performed in only 87 patients for alcohol related cirrhosis from a total of 2217 recipients over a seven year period (1985-92) in the UK; more recent data show a modest improvement. ${ }^{6}$ Recent trends suggest that alcohol consumption is increasing, especially among women, and that mortality from liver cirrhosis is also rising in the UK (fig 1).

This rise in UK cirrhosis mortality figures may also reflect the first impact of patients who acquired hepatitis $\mathrm{C}$ virus (HCV) infection. The current prevalence of this infection in the general UK population is unknown. Among 224000 consecutive asymptomatic blood donors in the northwest of England the prevalence of confirmed $\mathrm{HCV}$ infection was $0.04 \% .^{7}$ In another study in the West Midlands of a similar population $(n=287332)$, $0.02 \%$ were confirmed positive. ${ }^{8}$ These data would suggest a prevalence of between 200 and 400 patients per million population, a figure which is likely to be an underestimate with high risk populations and known carriers under-represented in this self-selected population. Indeed, in 1997, about 3000 new reports of HCV infection were notified to the Public Health Laboratory Services. This high figure reflects the initiative on screening high risk populations but lends some support to estimates of a higher UK prevalence. ${ }^{9}$ The number of injecting drug addicts currently in the UK is somewhere between 51900 and $77700^{10}$ and the prevalence of HCV antibody in this population is estimated at between $50 \%$ and $70 \% .{ }^{11}$ Introduction of blood donor screening and evidence of behavioural changes

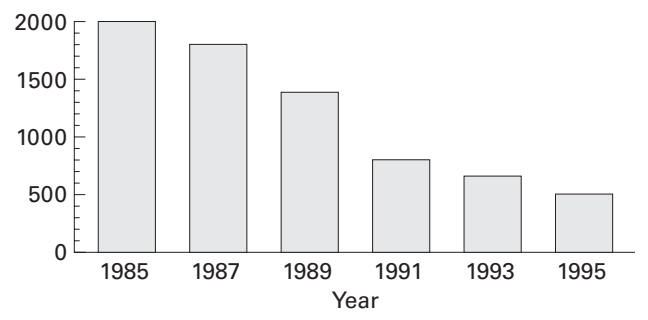

Figure 3 De novo acute hepatitis B infection in the United Kingdom.

in intravenous drug using populations has decreased the incidence of de novo infection in the United States dramatically (fig 2). ${ }^{12}$ Despite these recent trends, in the absence of efficacious treatment strategies, HCV related liver disease can be expected to become a major disease burden and indication for transplant in the future.

Hepatitis B virus (HBV) carriage is comparatively rare at a prevalence of $0.1-0.2 \%$ of the UK endogenous population (a low endemic country), with associated end stage liver disease a minor indication for transplantation. Higher chronic carriage rates are seen in males, and particularly following vertical or early childhood horizontal transmission (90\% carriage rate). In the UK, transmission is predominantly horizontal in association with high risk adult behaviours which lead to a carrier state in roughly $5-10 \%$ of cases. Vaccination, needle exchange programmes and screening of blood products, health care staff and pregnant women have reduced the incidence of acute infection steadily (fig 3). However, international travel, migrant populations from high endemic areas and sexual transmission can, in the absence of universal vaccination, be anticipated to sustain a detectable carriage rate.

The prevalence of primary biliary cirrhosis (PBC) worldwide is highly variable but is relatively common in the UK with recent figures from the north of England estimating a point prevalence of over 200 per million population. ${ }^{13} \mathrm{PBC}$ is presently the single largest indication for transplantation in the UK, unlike in Europe (viral liver disease) or the United States (viral cirrhosis recently outnumbering alcohol related liver disease).

The prevalence of primary sclerosing cholangitis (PSC) has only been crudely estimated by extrapolating data of its prevalence in the inflammatory bowel disease population and approximates to $20-40$ per million population. The annual incidence of autoimmune hepatitis (AIH) has been estimated at 6 per million. ${ }^{14}$

Paracetamol hepatotoxicity is the commonest cause of acute liver failure in the UK. ${ }^{15}$ Deliberate self-poisoning with this drug is commonest in young people, usually in the absence of any serious psychiatric morbidity. It is estimated that $30000-70000$ cases of paracetamol overdose reach medical attention and with an estimated case fatality of $0.4 \%$ represents approximately 130-270 deaths annually. Community availability of paracetamol is parallelled by its use in accidental overdoses and attempted suicide. In countries where 


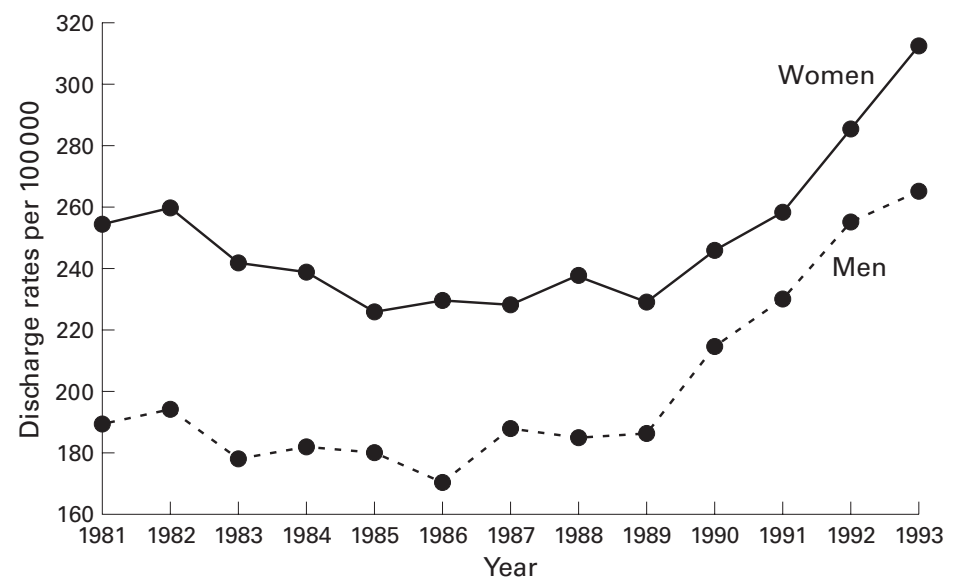

Figure 4 Importance of paracetamol overdoses in drug parasuicides in the United Kingdom.
Table 2 Indications for transplantation by primary disease in the United Kingdom (Fanuary 1985 to December 1992)

\begin{tabular}{ll}
\hline Disease & No (\%) of recipients \\
\hline Primary biliary cirrhosis & $464(21)$ \\
Autoimmune hepatitis & $142(6)$ \\
Hepatitis B & $79(4)$ \\
Primary sclerosing cholangitis & $136(6)$ \\
Alpha-1 antitrypsin deficiency & $51(2)$ \\
Budd-Chiari syndrome & $34(1)$ \\
Cryptogenic cirrhosis & $117(5)$ \\
Alcoholic cirrhosis & $87(4)$ \\
Biliary atresia & $161(7)$ \\
Acute liver failure & $351(16)$ \\
Hepatocellular carcinoma & $76(3)$ \\
Cholangiocarcinoma & $30(1)$ \\
Others & $489(24)$ \\
\hline
\end{tabular}

5.2 CURRENT STATUS OF LIVER

TRANSPLANTATION

Over 5000 liver transplants have now been performed in the UK. In 1997, 692 transplant procedures were performed in the UK and Republic of Ireland which equates to a rate of approximately 9-10 per million population (after adjustment for retransplants and nonnationals) per year. Total national numbers are increasing despite an overall fall in donors, although a plateau may be being reached. ${ }^{26}$ This has been achievable by use of previously considered marginal donors and through the surgical innovation of segmental reduction and split graft techniques. The mean recipient age has increased from 29.4 years in 1985 to 40.7 years in 1995. Patients transplanted for acute liver failure accounted for about $15 \%$ of all recipients. The data from the United Kingdom Transplant Support Service Authority (UKTSSA; table 2) do not show the very rapid rise in cases of $\mathrm{HCV}$ related liver damage which are now being referred to UK transplant programmes for assessment.

Central registries in the USA (Pitt-UNOS Liver Transplant Registry) and the European Liver Transplant Registry (ELTR) in Europe provide the best documentation on the current status of liver transplantation. These databases permit accurate determination of outcome in large numbers of patients in relation to a range of clinical and demographic characteristics. ${ }^{27-30}$ Patient survival has improved steadily, with a one year survival rate for all indications (acute and chronic liver disease) of $79 \%$ in Europe in 1995 (table 3). More experienced centres are achieving success in excess of $85 \%$. hepatitis A infection is increasingly seen in an older population who are known to have a higher mortality from this illness (fig 5). ${ }^{19}$ Indeterminate cases of acute liver failure, not attributable to any known virus (so-called nonA-E) have the highest mortality.

Drug induced hepatic disorders are rare causes of severe liver disease. ${ }^{20}$ However, roughly $5 \%$ of hepatotoxic reactions are lethal. Severe reactions resulting in death or transplantation which have been observed recently in UK clinical practice include antituberculous therapy, tetracyclines, ecstasy, flutamide, non-steroidal anti-inflammatory drugs (NSAIDs), and anticonvulsants. ${ }^{21-24}$ These reactions are usually idiosyncratic and unpredictable and, in relation to the overall level of NSAID usage, are very rare. ${ }^{25}$

\subsection{Natural history of liver disorders}

6.1 ACUTE LIVER FAILURE

Liver transplantation is an important treatment option in the management of severe cases of acute liver failure, although the process of selecting appropriate patients is problematic. ${ }^{31}$ The practical importance of accurate determination of prognosis has prompted several centres to examine systematically their experience of outcome and derive prognostic variables. $^{153233}$

\section{Course of illness}

The importance of the rate of onset of illness is a cardinal feature of acute liver failure. ${ }^{345}$ The 
Table 3 Patient survival according to the European Liver Transplant Registry (Fanuary 1988 to December 1996)

\begin{tabular}{ll}
\hline & $\begin{array}{l}\text { Patient survival } \\
(\%) \text { at 1 year }\end{array}$ \\
\hline All patients $(\mathrm{n}=19381)$ & 76 \\
Acute liver failure & \\
$\quad$ Fulminant hepatic failure $(\mathrm{n}=1311)$ & 61 \\
$\quad$ Subacute liver failure $(\mathrm{n}=101)$ & 69 \\
Hepatic malignancy & \\
Hepatocellular carcinoma $(\mathrm{n}=1344)$ & 67 \\
Cholangiocarcinoma $(\mathrm{n}=124)$ & 58 \\
Cirrhosis & 81 \\
Primary biliary cirrhosis $(\mathrm{n}=1939)$ & 80 \\
Alcoholic liver disease $(\mathrm{n}=2954)$ & 77 \\
Virus related cirrhosis $(\mathrm{n}=4631)$ & 81 \\
Primary sclerosing cholangitis $(\mathrm{n}=881)$ & 73 \\
Budd-Chiari syndrome $(\mathrm{n}=209)$ & 78 \\
Autoimmune cirrhosis $(\mathrm{n}=436)$ & 86 \\
Wilson's disease $(\mathrm{n}=182)$ & 82 \\
Secondary biliary cirrhosis $(\mathrm{n}=126)$ & \\
\hline
\end{tabular}

interval between the onset of jaundice and the development of encephalopathy has major prognostic implications. This paradoxical influence of the rapidity of the onset of encephalopathy is reflected in the favourable outcome of patients in whom this complication develops within seven days of the onset of jaundice (socalled hyperacute liver failure). In a historical study from King's College Hospital, London, the survival of a cohort of 81 cases in this group managed conservatively was $36 \%$, a figure which compares favourably with the survival rate of patients with acute liver failure (encephalopathy developing between eight and 28 days after jaundice) at $7 \%$, or subacute liver failure (jaundice to encephalopathy occurring between four and 12 weeks) at $14 \%$. More recent data show higher survival rates in the hyperacute group.

Aetiology and age

The aetiology of liver failure is the single most important variable predicting outcome. Cases categorised as of indeterminate (non A, non B) origin account for the largest proportion of the two unfavourable acute and subacute liver failure groups. Drug induced liver failure carries an intermediate prognosis although antituberculous drug cases may have a somewhat better prognosis. The prognosis with paracetamol hepatotoxicity is also more favourable and the best outcome is in pregnancy related syndromes. In paracetamol cases, risk factors for severe liver failure include delay in administration of $\mathrm{N}$-acetylcysteine, staggered overdose, preceding alcohol and anticonvulsant usage, and a background of chronic liver disease.

Among the viral hepatitides, hepatitis A virus has the best outcome, hepatitis B intermediate and non-A-E, which comprises the largest group in many series, the worst. ${ }^{36} 37$ In the series from King's College Hospital, the survival rates of these groups were $44.7 \%$, $34.4 \%$, and $9 \%$ respectively. Mortality is increased in patients at the extremes of age. ${ }^{19} 36$ The large VHSP study found that mortality in acute hepatitis was higher in patients over 50 or below 5 years of age.

Laboratory and coagulation parameters The increase in total serum bilirubin is recognised as the most important laboratory parameter in viral and drug cases, whereas low arterial $\mathrm{pH}$ (reflecting a metabolic acidosis) was found in the King's College Hospital study to be of foremost importance in cases of paracetamol induced liver damage. Derangement of quantitative liver function tests has also been correlated to outcome but is rarely used clinically. ${ }^{38-41}$ Changes in coagulation parameters are widely used for assessment of the severity of liver injury in ALF. The prolongation of prothrombin time and the more recently introduced international normalised ratio (INR) was shown in the King's College Hospital multivariate analysis to be an independent predictor of outcome regardless of aetiology. A rise in INR from days 3 to 4 after ingestion was associated with a $7 \%$ survival compared with a $79 \%$ survival in those whose INR fell at that time. $^{42}$ In a study of 115 patients with fulminant hepatitis $\mathrm{B}$, factor $\mathrm{V}$ values were lower in those who died and multivariate analysis confirmed this to be the most predictive indicator of outcome. ${ }^{43}$

Liver biopsy and volume assessment

Histological examination of a liver biopsy for regenerative activity and volumetric assessment of liver size has not been assessed formally and given the practical limitations, is only likely to be of clinical value in selected subacute cases. ${ }^{31}$

\subsection{CHRONIC LIVER DISEASE}

\subsubsection{Immune related disorders}

Autoimmune hepatitis - A consensus document on the criteria for the diagnosis and response to treatment of autoimmune hepatitis (AIH) has been published by an international panel. ${ }^{44}$ This disorder, which has a bimodal age distribution, is disproportionately represented among young patients with liver disease. ${ }^{45}$ The natural history of this disorder was examined in 106 patients in the King's College Hospital series and 69 patients in the Mayo Clinic series, with five year survival figures of $87 \%$ and $93 \%$ respectively. ${ }^{46} 47$ The presence or absence of cirrhosis at the time of presentation is of major prognostic importance-survival rates of greater than $90 \%$ at 10 years in its absence compared with about $50 \%$ with established cirrhosis alive at 12 years. ${ }^{48}$ Immunosuppression is indicated in patients with severe disease, particularly if there is bridging fibrosis at histological assessment. Symptomatic and biochemical improvement normally ensues although the disease often relapses rapidly when treatment is withdrawn early. ${ }^{49}$ Childhood onset, LKM positive and untreated disease have a bad prognosis. In the latter group, the survival falls to $50 \%$ at five years. Fulminant presentation, a rare occurrence, is usually resistant to immunosuppression. The optimal duration of therapy is unknown - five years has been suggested as reasonable - and any attempted withdrawal of immunosuppression should be performed cautiously particularly if there is established cirrhosis. ${ }^{50}$

Primary sclerosing cholangitis-Several studies have looked at prognostic variables and the natural history of this progressive cholestatic 
disorder. Most patients are symptomatic at presentation, although the correlation of symptoms with both histology and disease progression is unreliable. ${ }^{51}$ In a large north European study, median survival from the time of diagnosis to end stage disease was 12 years. ${ }^{52}$ Age, bilirubin concentration, splenomegaly, histological stage, and Child-Pugh score have consistently been shown to be the most important prognostic variables. ${ }^{53}{ }^{54}$ Three prognostic models have been derived from these studies but only the Mayo Clinic model assesses parameters predictive of death at the time of referral to a tertiary centre (see appendix I).

A risk score, using the latter model, of $\geqslant 5$ heralds a less than $50 \%$ chance of survival at one year. It should be recognised that clinical models which apply to populations have wide confidence limits when applied to individuals. The actuarial seven year survival of patients with Child-Pugh A, B and C disease has recently been calculated as $90 \%, 68 \%$, and $25 \%$ respectively. ${ }^{55}$

Several caveats in the natural history of PSC counsel against an over-reliance on a simplistic assessment of liver function when considering transplantation. The progression of this disorder can be highly variable and fluctuant with superadded cholangiocarcinoma and bacterial cholangitis complicating the clinical course. An abrupt elevation in bilirubin may reflect either disease progression, cholangitis, or the development of cholangiocarcinoma. Exclusion of this malignancy which presently carries a dismal prognosis (whether central or peripheral) is notoriously difficult and should be rigorously pursued. The risk of colonic dysplasia complicating inflammatory bowel disease (which is present in $60-70 \%$ of patients with PSC) is also increased by up to fivefold in these patients and demands colonoscopic surveillance in the transplant assessment. ${ }^{56}$ As PSC progresses to an advanced stage, malnutrition often ensues which further jeopardises the outcome of transplantation.

Primary biliary cirrhosis - The natural history of PBC is particularly well characterised with recent advances in recognition and understanding of this disorder. Untreated asymptomatic patients can expect a median survival of between 10 and 16 years whereas in symptomatic patients this declines to seven years. Whether the asymptomatic group should receive treatment is unknown. When the illness is advanced, the laboratory parameters - serum bilirubin, serum albumin and prothrombin time-are of prognostic value in estimating length of survival. A progressive cholestatic phase with a gradual decline in synthetic function is typical. Several prognostic models exist, some of which have undergone further refinement since initial development. These models are rarely applied to individual patients. ${ }^{57}$ Signs of fluid retention and variceal bleeding are also predictive of a decline in survival. Occasionally, portal hypertension complicates early PBC and can be managed without evaluation for liver transplantation. No pharmacological treatment has been shown to alter the course of advanced disease.
In early disease, several agents improve liver biochemistry and symptoms (colchicine, ursodeoxycholic acid (UDCA), cyclosporin, and methotrexate), and perhaps histological disease (methotrexate), but only UDCA seems to improve survival/delay transplantation. Its efficacy may be better in early disease and in combination regimens. The effect of UDCA on reducing bilirubin concentrations, but without greatly altering the natural history of advanced disease, may reduce the value of this laboratory indicator in assessing the timing for transplantation.

\subsubsection{Alcohol related disorders}

Ethnic origin, sex, and biochemical, nutritional, and immunogenetic factors are important in determining the susceptibility of the liver to alcohol. HCV infection and excessive alcohol intake have a moderately high coprevalence, especially in the more advanced forms of liver disease. ${ }^{58-60}$ Mortality from cirrhosis is strongly correlated with per capita alcohol consumption. Although consumption has declined significantly in many countries over the past two decades, the trend in recent years within the UK is less encouraging. The Health of the Nation initiative which set targets for reduction in consumption are not being met (amongst the male population $27 \%$ continue to consume alcohol above the recommended daily limits). ${ }^{61}$ Roughly $20 \%$ of alcoholics will develop cirrhosis although many are asymptomatic and undiagnosed during life. ${ }^{62}$

Several studies have determined the natural history of alcohol on liver morbidity and mortality. The spectrum of pathology in alcohol related liver disease, which is not simply a continuum of severity, correlates broadly with outcome. In a prospective study of 510 patients in the UK, the 10 year survival of patients who had steatosis on entry was $72 \%$, alcoholic hepatitis 57\%, active cirrhosis $49 \%$, and inactive cirrhosis $40 \% .{ }^{63}$ These survival figures are improvements on the early classic American studies suggesting improved management of complications ${ }^{64}$ Although alcohol consumption at the time of diagnosis has no influence on outcome, on-going misuse certainly reduces survival.

In alcoholic hepatitis serum bilirubin, prothrombin time and the presence of renal failure are important determinants of short term prognosis. ${ }^{65}{ }^{66}$ If the coagulation abnormalities are sufficiently satisfactory to allow a biopsy the hospital mortality is less than $15 \%$ whereas this figure rises to $42 \%$ if contraindicated. Short term mortality can be estimated by use of a discriminant function: 4.6 (prothrombin time - control time) + serum bilirubin (in $\mu \mathrm{mol} / \mathrm{l}) /$ 17.1. Values of 32 or greater denote severe disease with a four week mortality of greater than $35 \%$ and a two month mortality of $50 \% .{ }^{67} 68$

In patients with established cirrhosis, signs or symptoms of impaired liver function occurred at a rate of approximately $10 \%$ per annum and thereafter the median survival was reduced to 1.6 years. ${ }^{69}$ Overall, somewhere between $15 \%$ and $20 \%$ of cirrhotic patients will develop hepatocellular carcinoma and $75 \%$ will 
Table 4 Child-Pugh classification

\begin{tabular}{llll}
\hline & Grade 1 & Grade 2 & Grade 3 \\
\hline Encephalopathy & 0 & I/II & III/IV \\
Ascites & Absent & Mild & $>$ Moderate \\
Bilirubin $(\mu \mathrm{mol} / \mathrm{l})$ & $<34$ & $34-51$ & $>51$ \\
Albumin $(\mathrm{g} / \mathrm{l})$ & $>35$ & $28-35$ & $<28$ \\
INR & $<1.3$ & $1.3-1.5$ & $>1.5$ \\
\hline
\end{tabular}

Child-Pugh class: A, 6 or less; B, 7-9; C, 10 or greater.

INR, international normalised ratio.

die from liver related problems. ${ }^{70}$ The complications of spontaneous bacterial peritonitis and variceal haemorrhage carry a worse prognosis than ascites alone. ${ }^{71}$

The Combined Clinical and Laboratory Index (CCLI) is based upon 12 clinical and laboratory variables and yields a score which is predictive of the one year mortality. ${ }^{72}$ The Child-Pugh classification (table 4) requires fewer variables (serum albumin, serum bilirubin, prothrombin time, ascites, and encephalopathy) but is not specific for alcoholic liver disease. ${ }^{73}$ Significant portal hypertension (large oesophageal varices and/or a high hepatic vein pressure gradient) improve the prognostic accuracy of the Child-Turcotte classification system. ${ }^{74}$ Acute alcoholic hepatitis superimposed on cirrhosis or the presence of cholestasis are two particularly poor prognostic histological findings.

\subsubsection{Virus related disorders}

The natural history of hepatitis B surface antigen (HBsAg) carriage and associated liver disease is well characterised. Chronic HBV carriage is a dynamic state with viral-host interactions creating phases of replication, clearance, and reactivation. Liver damage occurs predominantly in the replication and seroconversion phases with reduction in activity following clearance. Most patients have no or minimal symptoms during these phases with clinical presentation often either following routine testing or following evolution of advanced liver disease.

Chronic hepatitis was present in $25 \%$ of asymptomatic HBsAg carriers. ${ }^{75}$ Annual calculated rates of evolution to cirrhosis vary between $1.5 \%$ and $5.9 \% .^{7677}$ Longitudinal studies in patients with chronic HBV hepatitis estimate the progression to cirrhosis at about $20 \%$ overall, ${ }^{77}$ although large fluctuations are present with the childhood infection cohorts experiencing up to a $40 \%$ frequency.

Once cirrhosis is established the five year survival in Child-Pugh grade $\mathrm{A}, \mathrm{B}$ and $\mathrm{C}$ categories was $83 \%, 79 \%$, and $30 \%$ respectively in a study from Taiwan. ${ }^{78} \mathrm{~A}$ more recent study from Europe observed a very similar five year survival figure of $84 \%$ in patients who had never experienced decompensation. Age, albumin, platelet count, splenomegaly, bilirubin, and eAg positivity at diagnosis correlate with survival. ${ }^{79}$ More rapidly progressive disease is observed with precore HBV variant infections. These mutant viruses are not endemic in the UK but are accompanied by increased rates of cirrhosis and mortality. ${ }^{80} 81$

In non-endemic countries such as the UK, superinfection with hepatitis delta virus (HDV) is predominantly restricted to intravenous drug users. Chronic HDV hepatitis supervenes in up to $90 \%$ of superinfections/co-infections and although some reports suggest a worse prognosis of the related liver disease, this is increasingly contentious. ${ }^{82} \mathrm{HBV}$ replication is often diminished and increased rates of clearance are seen.

In contradistinction to $\mathrm{HBV}$ infection, after infection with HCV most patients become chronic carriers. Disappearance of antibody and spontaneous clearance of HCV RNA are rare. Symptoms are often mild until features of advanced disease develop, a feature which contributes to late presentation. Regular screening is now performed in high risk groups and should reduce the current long interval from exposure to diagnosis. Among carriers, some $60 \%$ will develop a degree of chronic hepatitis, with progression to cirrhosis in about $20 \%$. The median interval from infection to cirrhosis is estimated at 30 years although large variations dependent on host factors exist. ${ }^{83}$ Evolution to cirrhosis was more frequent in patients who contracted the infection following blood product transmission $(23.4 \%)$ compared with drug users $(7.0 \%)$ in French populations (box 2)..$^{83}$

Box 2 Risk factors for progression to

hepatitis C cirrhosis (Poynard et al, ${ }^{83}$

Roudot-Thorval and colleagues ${ }^{84}$ )

- Alcohol intake

- Male sex

- Blood product transmission

- Hepatitis B co-infection

The natural history of $\mathrm{HCV}$ cirrhosis once established, in the absence of other liver co-factors, is surprisingly good with mortality from non-liver causes outweighing liver complications. Survival at five and 10 years is roughly $90 \%$ and $80 \%$ respectively, ${ }^{85}$ although once there has been an episode of liver decompensation the survival declines to $50 \%$ at five years. In Western European patients, superadded evolution of hepatocellular carcinoma occurs at a calculated annual incidence of about $1.5 \%$ per year. This complication is virtually restricted to patients with established cirrhosis. There is an emerging consensus that the genotypes common in the UK (1a, 1b, 2 and 3) have no direct correlation with viral load and debate on whether genotype $1 \mathrm{~b}$ accelerates disease progression per se continues. ${ }^{8687}$

\subsubsection{Hepatic malignancy}

Hepatocellular carcinoma-Five year survival of patients with this tumour has not improved over the past three decades. This statistic remains despite routine adoption of ultrasound imaging, which has possibly doubled the number of cases which are operable, and the introduction of a range of palliative treatment strategies. ${ }^{88}$ Mortality is related both to the tumour and the often co-existing cirrhosis. In low endemic countries such as the UK, the clinical presentation is often indolent and very commonly on a background of cirrhosis. All 
forms of cirrhosis increase the risk of HCC, although $\mathrm{HBV}, \mathrm{HCV}$, haemochromatosis, and tyrosinaemia are particular risks. In the UK, $\mathrm{HCV}$ is rapidly emerging as the principal risk factor for development of HCC. ${ }^{89}$ Tumour growth varies between patients and fluctuates within patients with a median doubling time estimated at four months..$^{91}$

The natural history is adversely affected by the Child-Pugh classification of the underlying cirrhosis and the tumour stage as assessed by tumour size and vascular invasion. ${ }^{92}$

Fibrolamellar tumour-The fibrolamellar variant of HCC characteristically occurs in young adults without chronic liver disease. Diagnosis is usually delayed and only made when the tumour is of substantial size and symptomatic. ${ }^{9394}$ It seems to have a slower doubling time than the conventional HCC variant. Fibrolamellar tumours are relatively insensitive to chemotherapy and, because of the size or location of the tumour masses, may be impossible to resect.

Cholangiocarcinoma-The prognosis of this rare tumour remains poor, with five year survival very uncommon in the absence of operative intervention. After either local or hepatic resection median survival is two years, with a five year survival of $15 \% .{ }^{95}$ Preoperative portal venous and biliary staging is essential in the selection of the few patients suitable for attempted resection. Palliative procedures to improve quality of life alongside adjuvant novel chemotherapy and radiotherapy schedules remain important, if unsatisfactory, treatment options in most patients. It is still unclear which palliative procedures are best (endoscopic versus percutaneous versus surgical). ${ }^{96}$ Moreover, the dosage, role of chemotherapy sensitising agents, and form of delivery of radiotherapy remain contentious. ${ }^{97-99}$

Epithelioid haemangioendothelioma - This a rare liver tumour which has a highly variable natural history and must be distinguished from angiosarcoma. ${ }^{100}$ Histological assessment is notoriously difficult and misleading, with this tumour on occasion resembling a chronic Budd-Chiari syndrome/veno-occlusive disease ${ }^{101}$ or cholangiocarcinoma. Factor VIII related antigen staining and arteriography are often required in diagnostic assessment. Tumour deposits are usually bilobar at presentation. Subtotal resection is an option and chemotherapy is ineffective.

Neuroendocrine tumours-Metastatic neuroendocrine tumours are slowly growing tumours which often metastasise to the liver. Multiple tumour nodules can lead to either local discomfort or excessive symptoms from hormone production. A variable response to chemotherapy is observed with eventual development of a resistant phase with bone involvement and the cachexia of advanced malignancy. Liver transplantation is considered for palliation when the tumour deposits are restricted to the liver.

\subsubsection{Budd-Chiari syndrome}

The clinical manifestation of the Budd-Chiari syndrome is variable, ranging from an insidious form with progressive ascites to a hyperacute presentation with liver failure. The precise indications for the available treatment options have become less clear. Early cases with good hepatic reserve can be managed medically or with radiological intervention. ${ }^{102}{ }^{103}$ In more severe cases urgent venous decompression or even transplantation is considered..$^{104} 105$ Transjugular intrahepatic portosystemic shunt (TIPS) is a non-surgical alternative to conventional shunting and does not lead to intraabdominal adhesions which might prejudice a subsequent transplant. ${ }^{106}$ Mesoatrial shunts may be valuable if there is retrohepatic caval compression. Advanced cirrhosis and significant impairment of liver function are indications for orthotopic liver transplant. ${ }^{107-109}$

\subsection{Liver transplantation}

7.1 HISTORY AND DEVELOPMENT

The first human liver transplants were performed by Starzl in 1963 with a further four years lapsing before there was a long term survivor. ${ }^{110111}$ These initial poor results predominantly reflected the limitations imposed by organ preservation, inadequate pharmacological control of rejection, and the occurrence of air embolism. After refinement of operative technique and anaesthetic care, other centres were encouraged to develop programmes in the late 1960 s and early 1970 s. ${ }^{112}$ Transplant numbers rose steadily in the next decade (1980-90) as patient survival rates of $80-90 \%$ at one year were regularly achieved in low risk elective recipients. As a result of these successes transplantation programmes have expanded rapidly such that annual totals now exceed those for heart recipients. Such a rapid expansion in liver transplantation may not continue as the number of donor organs available is appearing to plateau.

Given the success achieved with elective transplantation for chronic liver disorders, it was inevitable that emergency liver replacement with restoration of hepatic function would be attempted as a management option in ALF. Although renewed attempts are being made to develop artificial liver support which may radically change physicians' approach, at present transplantation has to be regarded as the optimal procedure for selected patients. In $\mathrm{ALF}$, despite the critical state of the patient, survival figures as high as $70-75 \%$ at one year are now possible. Current surgical methods are centred on whole organ orthotopic transplantation with the role of auxiliary partial orthotopic liver transplantation (APOLT) and of hepatectomy prior to organ retrieval remaining to be defined. A need for adequate back-up in intensive care and medical aftercare in obtaining good results with transplantation remains evident.

7.2 ORGANISATION OF TRANSPLANT SERVICES AND ORGAN ALLOCATION

The limitations in donor liver availability in the USA have focused debate on optimal use of this finite and scarce resource. Increasing numbers of patients on the waiting lists, longer 
waiting times and more patients dying while awaiting a donor organ are becoming more commonplace. ${ }^{113}$ The situation in the UK is less critical with cadaveric liver donor totals continuing to increase annually despite reductions in mortality from road traffic accidents. Waiting list mortality in the UK is still approximately $10 \%$ of the total (most related to emergency transplant list patients) with an unknown proportion of patients removed from the waiting lists because of irretrievable deterioration. Limitations in organ availability, however, are acute among small adults and the paediatric age group, although the recent innovative techniques of reduced and split grafts have extended the margins of organs utilised. Despite these developments, live related donation among infant and adolescent populations continues to be evaluated with encouraging early experience.

Strategies to maintain and improve organ procurement require further consideration. Wider use of elective ventilation procedures or non-heart beating cadaveric organs-leaving aside possible changes in organ donation legislation - may be required if waiting lists are not to grow further. ${ }^{114}$ International, and indeed regional, comparisons on procurement rates show surprising variability and further lessons should be drawn. Education both in the general population and within the health care profession in organ donor centres, alongside responding to feedback from reluctant relatives, continues to be urged.

Ethical considerations raised by rationing of donor organs or a hierarchical allocation are particularly contentious. ${ }^{115}$ This is especially pertinent in liver transplant programmes where a large proportion of end stage liver disorders reflect life style and are usually targeted for a more vigorous selection process. ${ }^{116}$ Add to the above pressures in patient selection, those of external audit, managed care, and academic competitiveness, it is not unexpected that programmes vary considerably in the rigour of this process. Over-refinement of selection may well achieve excellent post-transplant survival figures but have no impact on the overall survival figure of patients referred with end stage liver disease.

Within the UK and more recently in the USA, priority is accorded to patients with acute liver failure or where a transplant has failed in the early postoperative period. Further attempts to stratify disease severity with standardised criteria are welcome but would need to be verifiable. Accepted systems would need to accommodate the contesting claims of different patients. National audit of transplant outcome, which is now undertaken in the UK, may provide useful data.

In the UK, liver transplantation services within the National Health Service are supraregionally funded directly from the Department of Health (fig 6). The designated centres are responsible for assessment, surgery and post-transplant care of referred patients. A UK-wide national organ sharing scheme is co-ordinated by the United Kingdom Transplant Services Support Authority (UKTSSA),

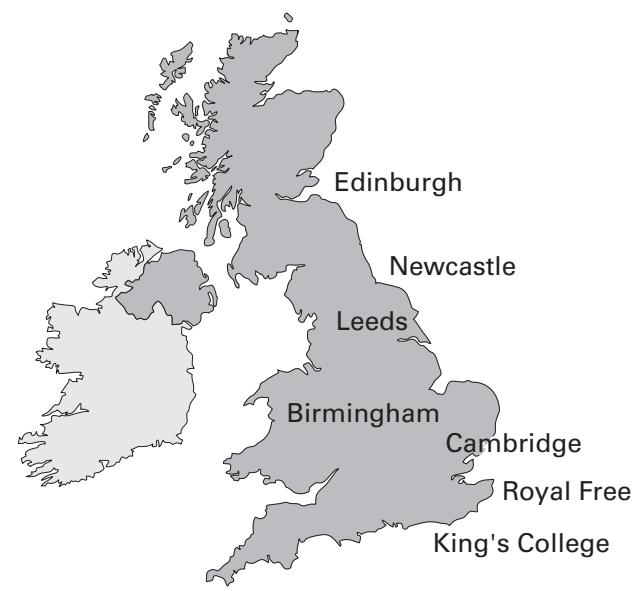

Figure 6 Supraregionally funded liver transplant centres in the United Kingdom.

Table 5 Patient survival in relation to the age (European Liver Transplant Registry Fanuary 1988 to December 1996)

\begin{tabular}{ll}
\hline Age (years) & $\begin{array}{l}\text { Patient survival (\%) at } \\
1 \text { year }\end{array}$ \\
\hline $15-45(\mathrm{n}=6455)$ & 78 \\
$45-60(\mathrm{n}=8265)$ & 74 \\
$>60(\mathrm{n}=2244)$ & 71 \\
Cirrhosis $(\mathrm{n}=1577)$ & 74 \\
Cancer $(\mathrm{n}=389)$ & 64 \\
Acute liver failure $(\mathrm{n}=103)$ & 51 \\
\hline
\end{tabular}

with a geographical zonal arrangement for organ retrieval.

7.3 OUTCOME AND SELECTION PROCESS FOR TRANSPLANTATION

\subsubsection{General considerations}

Patient survival rates vary modestly in relation to several demographic characteristics. Inferior survival rates have been noted with respect to age (young paediatric and older adult recipients), race (black and oriental recipients fared worse) in addition to the nature of the primary liver disease. Extremes of age were until recently considered relative contraindications to liver transplantation. In many programmes, however, older patients are now being transplanted with the mean age of all recipients rising consecutively in the ELTR from 35 years in 1985 to 43 years in 1992. An early report from Pittsburgh encouragingly reported no significant difference in survival in a cohort of 92 patients between 50 and 77 years of age compared with a group of adults 18-49 years old as well as a similar return to domestic activities. ${ }^{117}$ More recent data from both the Pitt-UNOS and the European registries indicated minor reductions in survival for patients over 60 years old (table 5). The differences are comparatively modest in the first few years post-transplant although of course they increase with time reflecting, for the most part, non-transplant related mortality. Transplant programmes now regularly assess patients in the 65-70 year age group, with rigorous evaluation of cardiorespiratory reserve. Overall, children have survival rates marginally higher than adults although those less than one year old fare less favourably mainly because of the higher rate of technical complications. 
Table 6 United Network Organ Sharing (UNOS) functional scale of patient status with data from the United States on liver recipients

\begin{tabular}{lll}
\hline I & Full-time employment & 5.8 \\
II & Part-time employment & 9.6 \\
III & Housebound & 38.3 \\
IV & Hospitalised & 22.7 \\
V & Intensive care unit & 9.9 \\
VI & ICU, life support & 13.6 \\
\hline
\end{tabular}

ICU, intensive care unit.

Although considerable experience and data are now available documenting the early outcome of liver transplant recipients limited experience has been reported concerning the clinical status and natural history of long term survivors. In a recent clinicopathological analysis, the prevalence of systemic and graft complications in recipients beyond five years post-transplant was described. ${ }^{118}$ Histological and biochemical abnormalities of the graft were unexpectedly common with normal biopsy samples present in a minority of patients only. Despite this high prevalence of graft pathology, morbidity and mortality are low, with attrition rates more favourable than for other organ recipients.

Transplantation should be considered actively in patients over 60 years of age. (Recommendation grade B.)

\subsubsection{Timing and referral}

Referral patterns influence post-transplant outcome and establishing an optimal practice will prevent potentially avoidable deaths. The contribution of the pretransplant clinical status of the recipient to overall outcome has assumed greater importance as waiting lists lengthen (with patient deterioration) and fewer deaths are attributable to vascular or technical perioperative events. Waiting time, in a blood group $\mathrm{O}$ recipient with a small habitus, at present in the UK can be up to nine months. The impact of pretransplant functional clinical status (as assessed by the six-point United Network for Organ Sharing (UNOS) score which can be applied to all liver candidates) correlates both with survival and length of hospital stay and total costs of transplantation. Pitt-UNOS registry data show a one year patient survival rate of $84.4 \%$ versus $60.1 \%$ between recipients in the best (I) and worst categories (VI) of this functional scale, respectively (table 6).

The need for accurate assessment of prognosis in liver disorders - which can be the basis of evaluating the need for transplantation or other treatment-has led to number of landmark studies in the development of clinical prognostic models. ${ }^{53}{ }^{64119-121}$ Of these the natu-

Table 7 Impact of advanced disease and outcome of transplantation in primary biliary cirrhosis

\begin{tabular}{llll}
\hline Mayo score (Wiesner et $a l^{127 a}$ ) & 6.3 & 7.9 & 9.5 \\
ICU (days) & 2.5 & 4 & 9 \\
Hospital (days) & 28 & 33 & 37 \\
Total cost (\$/ $£$ ) & 114783 & 149917 & 200680 \\
& $(71739)$ & $(93698)$ & $(125425)$ \\
European score (Neuberger et al $^{127 b}$ ) & $<6$ & $6-7.2$ & $>7.2$ \\
Patient survival (1 year) & $78 \%$ & $63 \%$ & $50 \%$ \\
\hline
\end{tabular}

All values are expressed as medians. ral history of $\mathrm{PBC}$ is the best validated and the model has also been used to examine the relation between disease severity at the time of transplantation and outcome. ${ }^{122-124}$ Late referrals for transplantation at advanced stages of disease as denoted by higher serum bilirubin values and a raised prognostic index were reflected in lower post-transplant survival (table 7). At the time of referral, the estimated median survival in the absence of transplantation was only four to six months in the Birmingham study. Stratification for risk scores, using the Mayo Clinic model, in patients with PBC now also makes it possible to delineate outcome in different severity categories in relation to morbidity and costs. ${ }^{125}$ Reduced hospitalisation and costs were found for those transplanted with lower risk scores, namely earlier in the natural history.

A recent large American study further confirmed the influence of pretransplant renal dysfunction, age, Child-Pugh grade, and the UNOS status on outcome in both PSC and PBC recipients. ${ }^{126}$ All of these variables will deteriorate with delays in referral and/or waiting time and have been found in smaller previous studies to correlate, irrespective of the underlying disease, with outcome. ${ }^{127}$

Once a patient with cirrhosis is admitted to an intensive care unit the prognosis, in the absence of transplantation, is extremely poor. ${ }^{128}{ }^{129}$ Protein calorie malnutrition is common in chronic liver disease and is also associated with an inferior post-transplant outcome. ${ }^{130-132}$ Late referral is likely to be associated with a worse nutritional status.

- Potential candidates should be assessed on the basis of:

(i) profile of complications;

(ii) calculated prognosis;

(iii) quality of life.

(Recommendation grade C.)

- Early referral of potential candidates to transplant programmes facilitates the timing and outcome of transplantation. (Recommendation grade B.)

- Referral, and hence transplantation, should preferably occur before the development of malnutrition, hepatorenal failure, and an advanced UNOS score (see appendix I for UNOS grading system). (Recommendation grade B.)

\subsubsection{Disease specific factors}

Acute liver failure-Early recognition and prompt referral of cases of acute liver failure to centres where intensive medical therapy and transplantation are available is continuing to improve the outcome. ${ }^{133}$ In paracetamol induced liver failure, the comparative lack of precision in predicting outcome early in the disease, combined with the potential for rapid progression are circumstances which should encourage early referral. A significant proportion of cases will make an unremarkable recovery without intensive measures but this level of unnecessary transfer is justified if the 
Table 8 King's College Hospital criteria for transplantation in acute liver failure

Paracetamol

- $\mathrm{pH}<7.30$ (irrespective of grade of encephalopathy) or

- Prothrombin time $>100$ seconds and serum creatinine $>300 \mu \mathrm{mol} / \mathrm{l}$ if in grade III or IV coma Non-paracetamol

- Prothrombin time $>100$ seconds (irrespective of grade of encephalopathy) or

- Any three of the following (irrespective of grade of encephalopathy):

(i) aetiology: non-A, non-B (indeterminate) hepatitis, halothane hepatitis, idiosyncratic drug reactions

(ii) age $<10$ or $>40$ years

(iii) jaundice to encephalopathy interval $>7$ days

(iv) prothrombin time $>50$ seconds

(v) serum bilirubin $>300 \mu \mathrm{mol} / 1$

potential for transplantation, in what is often a narrow window of time, is to be realised. ${ }^{134}$

In cases of paracetamol hepatotoxicity, the guidelines given in table 1 for referral to a specialist liver failure and transplant centre are proposed. (Recommendation grade C.)

In the event of deterioration, two principal criteria are used in assessing the need for transplantation. On the basis of their findings, the Clichy group use the presence of encephalopathy and measurement of factor $\mathrm{V}$ concentrations in identifying candidates for transplantation. The King's College Hospital guidelines (table 8) are based on two principals: (1) they are applicable early in the hospital admission and (2) use readily available clinical or laboratory parameters. ${ }^{15}$

In paracetamol hepatotoxicity, arterial $\mathrm{pH}$ can be used irrespective of encephalopathy or in those who have developed encephalopathy in combination with a large increase in prothrombin time and serum creatinine. In nonparacetamol patients, the aetiology, speed of onset of encephalopathy, and the degree of liver impairment are used. All criteria in the latter patients are independent of the grade of encephalopathy and, as has been shown in a recent evaluation, are applicable early in the course of the illness. ${ }^{135}$ Further improvements in sensitivity and on-going validation, in the light of changes in medical treatment, are needed.

Despite attaining criteria for a poor survival, a large proportion of patients selected are not ultimately transplanted. Delays in organ availability and occasionally referral may allow establishment of the severe complications of liver failure (sepsis, cardiovascular disturbances and respiratory failure, cerebral oedema). Psychiatric stability, which is relevant in paracetamol cases, is often difficult to assess fully at the time transplantation is being considered. Major psychiatric sequelae after transplantation may occur and often manifest in non-compliance with immunosuppression. ${ }^{136}$ The outcome of orthotopic liver transplantation is again linked to the severity of the pretransplant clinical status in this population. ${ }^{137}$

Most criteria used in the selection of patients for transplantation identify those with an estimated short term survival of between $10 \%$ and $20 \%$. This contrasts with the five year survival rate of $51 \%$ for 383 patients with acute liver failure in the UK between 1985 and 1994. No difference in outcome among the different aetiological categories of ALF with the notable favourable exception of fulminant Wilson's disease has been seen. ${ }^{138-140}$

Patients with non-paracetamol acute and subacute liver failure (defined by the presence of encephalopathy) (including fulminant Wilson's disease) should be referred to a transplant centre. (Recommendation grade B.)

- Patients with non-paracetamol liver failure and a progressive coagulopathy in the absence of encephalopathy should be discussed with a transplant centre. (Recommendation grade C.)

PRIMARY BILIARY CIRRHOSIS AND PRIMARY SCLEROSING CHOLANGITIS

Transplantation for PBC can be indicated for both prognosis in end stage disease and for symptomatic relief of intractable pruritus or debilitating lethargy. The outcome of transplantation is good with even historical registry figures (1988-96) showing over $80 \%$ one year patient survival. ${ }^{138} 140$ In a study from a small European centre, the estimated survival of simulated controls based on three separate prognostic models-Mayo, AZG, and Christensen models - was consistently reduced compared with that achievable with transplantation. ${ }^{141}$ Although recurrence of PBC in the liver graft is evident histologically in a proportion of cases, there have been no reported cases of subsequent graft failure.

- Primary biliary cirrhosis is an excellent indication for transplantation. (Recommendation grade A.)

- Prognostic and palliative indications are both justified. (Recommendation grade C.)

- Referral should be made once the serum bilirubin exceeds $100 \mu \mathrm{mol} / 1$ or significant impairment of liver function ensues. (Recommendation grade B.)

- Earlier referral is justified if symptoms or complications are prominent. (Recommendation grade C.)

The outcome of transplantation for PSC is generally good. In a European comparison where survival was calculated from one of the validated prognostic models, actuarial survival at five years was $89 \%$ in those transplanted versus $31 \%$ in those managed conservatively. ${ }^{142}$ Similar results have been obtained, again using simulated controls, in an earlier study from Pittsburgh $(73 \%$ versus $28 \%$ actuarial five year survival). ${ }^{143}$ Incidental, as opposed to previously diagnosed, cholangiocarcinoma, detected at microscopy or less than $1 \mathrm{~cm}$ in the explanted liver, does not have a major impact on outcome. ${ }^{144}$ Although recurrent cholangiopathy can be detected in up to $32 \%$ of patients this has not led to any significant deterioration in graft or patient survival. ${ }^{145}{ }^{146}$ The concern over the devastating development of cholangiocarcinoma superseding PSC has led to centres urging early referral of patients for transplantation. ${ }^{142} 147148$ 


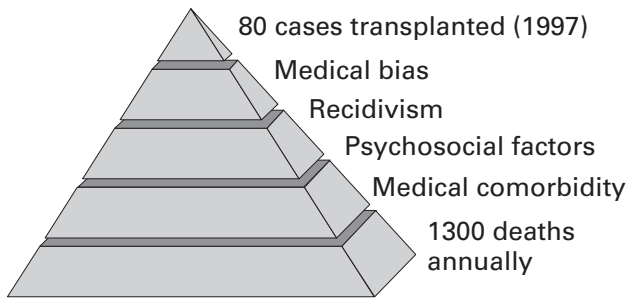

Figure 7 Possible reasons for low rate of transplantation in alcoholic liver disease.

The Hannover group have detected malignancy when the Mayo model score exceeded four at a prevalence of $33 \%$; a cohort of patients whose prognosis, managed medically without the tumour, would have been acceptable at just under $70 \%$ at five years. Earlier referral for transplantation in this condition should increase the number of suitable tumour-free candidates and avoid significant pretransplant deterioration which jeopardises outcome as previously discussed (see section 6.2.1). ${ }^{126}$

- The optimal timing of transplantation in PSC has not been defined and hence early referral is recommended. (Recommendation grade B.)

- Stringent efforts to detect superadded cholangiocarcinoma are necessary but these are suboptimal and unreliable. (Recommendation grade B.)

- A Mayo model score of five or greater or a Child grade $\mathrm{C}$ score justifies referral for transplantation. (Recommendation grade B.)

AUTOIMMUNE HEPATITIS

Failure to achieve histological remission despite immunosuppression at four years in chronic cases is associated with a poor prognosis in the absence of transplantation. ${ }^{149}$ In acute cases, failure to achieve an early and rapid response to corticosteroids merits transplant consideration especially in the context of shrinking liver volume. However, the presence of severe liver disease at presentation (including cirrhosis or encephalopathy) does not preclude a good response to immunosuppression. The outcome of AIH following transplantation in all age groups is generally good. However, this disease can recur in a significant proportion of patients and can lead to graft injury. This has been associated with comparatively low maintenance immunosuppression regimens, particularly where azathioprine and prednisolone have been either withdrawn or minimised. Long term data on the outcome of these patients are awaited.

- Transplantation is a viable option for AIH although at present the data are comparatively short term and limited. (Recommendation grade B.)

- Failure to achieve biochemical remission, shrinking liver volume, severe acute presentation, and progressive decompensation in chronic cases are indications for transplant assessment. (Recommendation grade B.)
ALCOHOL RELATED LIVER DISEASE

Three main issues impact on the evaluation of this disorder for transplantation:

- Is there a potentially reversible element to the disease following alcohol abstinence?

- Is the alcoholic liver disease associated with alcohol dependence and can this condition be managed adequately to achieve abstinence?

- Are there other comorbid alcohol related illnesses which will jeopardise the outcome? The difficulties in answering these questions, alongside the social context of alcohol use, have biased transplant programmes to give priority to non-alcoholic liver disease (fig 7). One estimate is that roughly 250 patients with alcohol related disease each year in the UK could be suitable for liver transplantation equating to about four per million population per year. ${ }^{4}$ Similarly, alcoholic cirrhosis is responsible for more than 11000 deaths in the USA annually but transplantation is only performed in about $6 \% .^{150}$

Initial assessment of patients is aimed at evaluating the degree to which a superimposed acute and potentially reversible acute alcoholic hepatitis is present. Supportive therapy and abstinence can allow recovery although in cases of alcoholic hepatitis admitted to hospital, the four week mortality is as high as $50 \%{ }^{151}$ Several issues have constrained the use of transplantation in severe alcoholic hepatitis-on-going alcohol use, severe liver impairment, risk of infection, hepatorenal syndrome, and the inability to assess comorbid medical and psychiatric characteristics adequately. Reports on the efficacy of transplantation in what are often a young cohort of patients are limited. ${ }^{152}$ The outcome was similar to that of patients with alcoholic cirrhosis.

The synergism of hepatitis $C$ infection and alcohol usage in exacerbating liver damage, particularly in men, is evident. Anecdotally, these patients seem to be emerging rapidly as the largest group presently being referred for transplantation.

It is an important part of the selection process to differentiate transplant candidates who suffer from alcoholism as opposed to those who were susceptible to moderate non-dependent alcohol use. The latter who retain control of alcohol use have a good prognosis following transplantation. Once a diagnosis of alcoholism has been established, however, it is necessary to assess the likelihood of future sobriety. A rating scale, devised by Beresford, relies on the seminal studies of Vaillant and Strauss and Bacon to identify those factors associated with sobriety. ${ }^{153-155}$ Comorbid psychiatric disease, intercurrent drug dependence, acceptance of dependence by the patient, social stability, and previous drinking patterns have to be considered alongside the four favourable prognostic factors of Vaillant (activity that structures time, a rehabilitation relationship, source of hope or self-esteem, and noxious consequences of on-going use). Given the complexity of these factors, psychiatric assistance is an essential component to the multidisciplinary selection process. Nevertheless, prediction of recidivism is inexact and further evaluation of risk factors is required. ${ }^{156}$ 
Comorbid end-organ damage from alcohol needs to be assessed carefully prior to selection for transplantation. Many of these complications will make the transplant hazardous or rehabilitation unsatisfactory. Organic brain damage from chronic alcohol use, whether cerebellar disease, Korsakoff's syndrome, or cerebral atrophy, needs to be distinguished from hepatic encephalopathy. ${ }^{157}$ Difficulties in differentiating these processes and estimating posttransplant recovery have been widely observed. The abnormalities present on computed tomography and magnetic resonance image scanning poorly correlate with functional impairment. Regardless, psychomotor and abstracting abilities can improve to some degree after transplantation. ${ }^{158}$ Alcoholic cardiomyopathy with myocardial dysfunction needs to be sought rigorously as preservation of an adequate cardiac output is a major determinant of early transplant outcome. Myocardial dysfunction is usually indicative of on-going alcohol use. ${ }^{159}$ Alcoholic myopathy also usually improves with abstinence, and is rarely of importance in the selection process. Pancreatitis is surprisingly rare in patients with ALD but can be problematic if present. ${ }^{160}$ Protein-calorie malnutrition may be present in up to $55 \%$ of alcoholic cirrhotic patients. ${ }^{161} 162$

An enforced and supervised period of abstinence in the community, prior to transplantation, is regularly encouraged and occasionally mandatory. Such an interval (which is arbitrarily often six months in clinical practice) may serve two purposes: it allows any residual element of recovery in the liver to occur and enters the potential recipient into a contract with the transplant programme. If the patient still has severe decompensated cirrhosis, a significant improvement in survival with the use of transplantation can be anticipated. ${ }^{163}$ The on-going French study which uses simulated and actual controls matched for disease severity, age, and bleeding history is now reporting a survival benefit for transplantation at five years in medium risk patients (Child-Pugh score 7-10).

Despite the apparent difficulties in selecting patients, transplant programmes are reporting that sustained and serious recidivism rates are unexpectedly low. Although questionnaire and interview based studies may not be optimal and deliver variable rates of alcohol use, it is evident that serious drinking patterns are not usually sustained after transplant. If there is still some debate about actual levels of alcohol usage, the more reliable data points of histological recurrence and post-transplant mortality figures further indicate that disease recurrence plays a minor role in the overall outcome of this population. ${ }^{164}$ This observation has generated several explanations for the recipients modified behaviour which include medical consequences, compulsory supervision, substitute dependency, and improved esteem. ${ }^{165}$ The most recent liver transplant registry data from the United States demonstrate that survival figures for ALD are similar to non-ALD, chronic liver disease, indications. ${ }^{140}$ These figures have been achieved despite a generally sicker pretransplant clinical status. Lower rejection rates may be a part of the explanation.

- Reasons for the apparent low level of referral of patients with alcoholic liver disease for transplantation need to be elucidated. (Recommendation grade C.)

- Transplantation in selected patients with advanced ALD can improve outcome. (Recommendation grade A.)

- A six month period of supervised community abstinence is desirable but not mandatory. (Recommendation grade B.)

- Young patients on first medical presentation may not need to undergo the usual stringent evaluation if the illness is life threatening. (Recommendation grade C.)

- Psychosocial assessment should be performed by a multidisciplinary transplant team. (Recommendation grade B.)

- Alcohol dependence should be differentiated from non-dependent misuse. (Recommendation grade B.)

- Exclusion of significant comorbid disease is an essential element of assessment. (Recommendation grade B.)

\section{HEPATITIS B LIVER DISEASE}

Antiviral therapy does not modify the course of HBV related liver disease once cirrhosis is established. Accordingly, transplantation is the only usual option open to patients who go on to develop end stage disease. Recurrence of HBV related liver disease is the main determinant of outcome after transplantation in this population, as liver replacement per se does not prevent virological recurrence from extrahepatic reservoir sites. Virological, histological, and ultimately clinical disease recurrence are closely related to the pretransplant replication status and the presence of delta virus co-infection. Measurement of $\mathrm{HBe}$ antigen and circulating HBV DNA is mandatory prior to transplant. Infection with precore mutants of HBV does not seem to affect the outcome of transplantation. ${ }^{166}$ The natural history of HBV infection unaffected by recipient selection or pharmacological intervention has been documented. ${ }^{167} 168$ These results indicated that active viral replication at the time of transplantation heralded an inferior outcome. This group of patients could not have continued to be justified as candidates for transplantation were it not for the reduction and/or delay in recurrence with long term passive immunoprophylaxis (hepatitis B immunoglobulin) and more recently pharmacological interventions. ${ }^{169-171}$ Co-infection with hepatitis delta virus (HDV) is advantageous for both disease recurrence and survival. Lamivudine has potential use in optimising the outcome after transplantation. ${ }^{171}$ However, concerns about the emergence of $\mathrm{HBV}$ variants with resistance to this agent, when used as monotherapy, are now prevalent. The site of the mutations and in vitro resistance accompanied by breakthrough serological recurrence are now known. The clinical 
impact of these mutations is not yet clear, however, with interim analysis of on-going trials awaited. Ganciclovir and famciclovir seem to be less effective.

- Patients with end stage chronic HBV related liver disease must be HBV DNA negative before transplantation. (Recommendation grade B.) HBV DNA negativity is based on commercial nonPCR based assays.

- Most HBV DNA positive patients can be rendered HBV DNA negative with antiviral treatment and should not be excluded from assessment. (Recommendation grade B.)

- Long term passive immunisation with hepatitis B immunoglobulin is an effective strategy to prevent reinfection. (Recommendation grade A.)

- Mutant HBV or HDV coinfection are not contraindications to transplantation. (Recommendation grade B.)

HEPATITIS C LIVER DAMAGE

Survival after transplantation for hepatitis C cirrhosis is comparable with other indications. ${ }^{172}$ Although recurrence of the virus, again from reservoir sites, is universal and indeed levels of viraemia are increased, the presently documented impact on graft function and survival, at least in the medium term, is limited. Genotype HCV-1b may be associated with increased graft damage. The influence of viral load and adjuvant interferon therapy are contentious and do not influence patient selection. High dose immunosuppression increases viraemia and cumulative exposure may promote disease recurrence. Further studies are required before conclusions on whether disease recurrence will affect long term graft survival can be reached. Concomitant $\mathrm{HCC}$ is a major risk in end stage $\mathrm{HCV}$ cirrhosis but in carefully selected patients has no effect on post-transplant survival. ${ }^{173}$ Early reports on the efficacy and safety of transplantation in haemophiliacs with HCV infection are encouraging but further experience is needed and continuing assessment seems justified. ${ }^{174} 175$

- Patients with end stage hepatitis C cirrhosis should be considered for transplantation. (Recommendation grade B.)

- Genotype and viral load should not influence transplant assessment. (Recommendation grade B.)

- On-going drug dependency is a relative contraindication to transplantation. (Recommendation grade B.)

- Alcohol misuse should be actively excluded in HCV cases. (Recommendation grade $\mathrm{B}$.)

- Haemophilia is not a contraindication to transplantation. (Recommendation grade C.)
HEPATIC TUMOURS

Hepatocellular carcinoma

Patients with liver malignancy were the initial volunteers in the pioneering days of transplantation. This population was chosen because of its poor prognosis with conservative treatment and the absence of comorbidity from end stage liver disease. Enthusiasm quickly waned when recurrence of tumour quickly emerged as the limiting factor in survival. ${ }^{176}$ Over time, experience with refinement in the selection process has improved results with the role of transplantation now more clearly defined. The report from Penn in 1991 of 637 liver malignancies is presently the best available data documenting outcome after transplantation. ${ }^{177}$

Transplantation is rarely indicated in HCC developing within a non-cirrhotic liver unless there are surgical contraindications. Resection was superior to transplantation in two studies, although a bias towards irresectable cases in the transplant groups may exist. ${ }^{178} 179$

The optimal management of HCC complicating cirrhosis is more problematic. ${ }^{180}$ An evaluation of the likelihood of both postoperative and medium term decompensation from the underlying cirrhosis, and obtaining tumour-free resection margins needs to be calculated before choosing resection as the preferred treatment. Mortality is certainly increased postoperatively in cirrhotic compared with non-cirrhotic patients, with the risk of complications aggravated by the presence of portal hypertension, a high Child-Pugh score, and the number of liver segments resected. ${ }^{181-183}$ Resection is contraindicated in patients with Child grade C (0-12\% survival at three years), and is of only selected use in patients with Child grade B (35\% three year survival) disease. Careful assessment of liver reserve (this may include measurement of portal pressure) and the use of hepatic vascular occlusion intraoperatively should improve outcome.

Lymph node or macroscopic vascular invasion also have a major adverse impact on survival. Two groups have reported a dismal survival (three to 18 months) in these patients. ${ }^{179}{ }^{184-186}$ Accurate TNM staging, however, is often only possible after operative and pathological examination of the explanted liver. ${ }^{187}$

Aggravated recurrence of $\mathrm{HBV}$ related disease in cases complicated by HCC may relate to immunological defects or the influence of adjuvant chemotherapy. There is no firm consensus regarding the indications, dosage regimens, or timing of adjuvant systemic chemotherapy or arterial chemoembolisation in the peritransplant period. ${ }^{188-191}$

Transcatheter arterial chemoembolisation is not effective in patients in whom both surgery and transplantation are contraindicated. ${ }^{192}$ Percutaneous ethanol injection may be of value in Child grade A cirrhosis and there is encouraging but uncontrolled evidence in other 
groups. ${ }^{193}$ Controlled data on both tamoxifen and systemic doxorubicin show no survival benefit. ${ }^{194} 195$

- Transplantation is recommended for most small hepatocellular carcinomas complicating cirrhosis. (Recommendation grade A.)

- Tumours $>5 \mathrm{~cm}$ or greater than three in number should only be assessed in conjunction with a novel management strategy. (Recommendation grade B.)

- Local or systemic extrahepatic HCC disease is an absolute contraindication to transplantation. (Recommendation grade A.)

\section{Fibrolamellar hepatocellular carcinoma}

At the time of diagnosis and consideration for transplantation these tumours are often at advanced stages with multifocal involvement. ${ }^{185196197}$ Despite this in the 33 patients identified by Penn, although disease recurrence was seen in 39\%, the actuarial survival was $55 \%$ at five years. This survival figure is considerably better than that seen in HCC. Overall the data show that fibrolamellar HCC is a slower growing, less aggressive tumour with recurrent deposits appearing at a later stage after transplantation.

- The fibrolamellar variant of HCC is not constrained by the size and volume criteria for transplantation. (Recommendation grade $\mathrm{A}$.)

Primary cholangiocarcinoma

Overall results of transplantation are discouraging, with early recurrence of this tumour common. In 109 reviewed cases, 44\% had recurrent disease (within 12 months in $52 \%$, and within two years in $70 \%$ ) with a five year patient survival of $17 \% .{ }^{177}$ No significant difference in outcome between Klatskin or peripheral lesions is observed. ${ }^{198}$ The importance of intraoperative staging and posttransplant prognosis was examined by local lymph node disease in hilar tumours. ${ }^{199}$ Two year survival figures of $83 \%$ without nodal involvement and $0 \%$ with metastatic involvement were observed. Incidental microscopic disease found on examination of the explanted liver is a small subgroup where transplantation may be successful. Even the abdominal organ cluster transplant, pioneered by Pittsburgh, has reported a disappointing $20 \%$ survival rate at three years. ${ }^{200}$ Radical surgery may well be a better option than transplantation. ${ }^{201202}$

- Cholangiocarcinoma is not an indication for transplantation unless in conjunction with a novel management strategy. (Recommendation grade $\mathrm{A}$.)
Epithelioid haemangioendothelioma

Five year survival figures between 43\% and $76 \%$ have been reported. ${ }^{177} 203$ These figures were achieved despite extensive disease, with extrahepatic disease not seeming to affect survival. Distinguishing this tumour from an angiosarcoma is essential as transplantation is followed by universal recurrence and early mortality in the latter.

- Patients with epithelioid haemangioendothelioma should be referred for expert histopathological and radiological opinion to exclude angiosarcoma. (Recommendation grade B.)

- Extrahepatic disease may not be a contraindication to transplantation in epithelioid haemangioendothelioma although this varies from centre to centre. (Recommendation grade B.)

\section{Metastatic disease}

In neuroendocrine tumours, several reports confirm that worthwhile symptomatic relief, and on occasion cure, can result from transplantation where resection is not feasible. ${ }^{204-207}$ Although disease recurrence is common, good medium term palliation can be achieved. Carcinoid tumours had a better survival than non-carcinoid neuroendocrine tumours in a large French series. ${ }^{208}$ The overall results of transplantation for nonneuroendocrine liver metastases have been poor, with recurrence and early death being the rule. ${ }^{198}$

- Neuroendocrine tumours are the only metastatic liver tumours suitable to be transplanted for palliation. (Recommendation grade A.)

- Extrahepatic disease from neuroendocrine tumours is a contraindication to transplantation. (Recommendation grade A.)

\section{Budd-Chiari syndrome}

Transplantation is an option in severe acute Budd-Chiari syndrome, in decompensated cirrhosis, failed shunt surgery, and where there is caval compression. Several surgical and medical issues are important in the assessment of a patient with Budd-Chiari syndrome. Adhesions in the region of the suprahepatic inferior vena cava, following previous surgery, and an increased risk of portal venous thrombosis can complicate surgery. ${ }^{209}$ Medically, malignant infiltration of the liver needs to be excluded and the underlying procoagulant disorder characterised. Post-transplant anticoagulation has improved survival dramatically. ${ }^{210}$

The criteria upon which to base the decision to perform some form of portosystemic shunt 
or proceed to transplantation are poorly defined. An estimation of the severity of portal hypertension and irreversible decompensation needs to be made. Given the not infrequent and successful use of transplantation to rescue patients following failed shunt surgery, a case for performing all surgery in transplant centres can be made. ${ }^{211}{ }^{212}$ Five year survival figures of $67 \%$ and $69 \%$ were obtained in cohorts of patients who were considered to be either too ill to perform decompressive surgery or who failed this procedure. ${ }^{212} 213$ These survival figures, in a population which is at the sickest end of the clinical spectrum, are encouraging.

- Budd-Chiari syndrome is optimally managed in a centre offering the four main therapeutic options of decompressive surgery, transplantation, TIPS, and radiological intervention. (Recommendation grade $\mathrm{B}$.)

Rare indications

Wilson's disease-A fulminant clinical course of Wilson's disease is a rare presentation which, particularly in the presence of haemolysis and renal failure, is rarely controlled by medical treatment. In more insidious presentations with signs of chronic liver disease, stabilisation may be achieved with chelation therapy. Transplantation has been used successfully in advanced liver disease, following non-compliance with treatment, in severe neurological impairment, and in the fulminant presentation. ${ }^{139}$ In decompensated cirrhosis during childhood, the King's College Hospital prognostic index remains valid. ${ }^{214}$ The balance between persevering with medical therapy or opting for transplantation in newly diagnosed adult cases, with established cirrhosis, is still unclear.

- Wilson's disease is a good indication for transplantation. (Recommendation grade B.)

Genetic haemochromatosis-Data on the outcome of transplantation for haemochromatosis are limited. ${ }^{215} \mathrm{~A}$ recent report supports anecdotal evidence that somewhat inferior survival figures are observed secondary both to early postoperative deaths and later cardiac related mortality. ${ }^{216}$ Extrahepatic iron loading (cardiac and pituitary function particularly) can complicate transplantation.

- Transplantation for genetic haemochromatosis is a viable option but should be considered a higher risk procedure than in other elective indications. (Recommendation grade $\mathrm{C}$.)
Amyloidosis-Familial (autosomal dominant) amyloid polyneuropathy (FAP) is a rare indication for transplantation. Different variants of FAP exist and are described by the geographical location of affected pedigrees; the commonest is the Met-30 variant. The disease is often ultimately fatal, with inexorable amyloid deposition and damage to the peripheral and autonomic nervous system, kidneys, heart, and eyes. Cardiac and renal function require rigorous evaluation during the preoperative investigations. Postoperative intensive care is complicated by impairment of the autonomic cardiovascular reflexes and placement of a temporary pacemaker perioperatively is often required. ${ }^{217}$ Stabilisation of neurological and gastrointestinal, if not cardiac, disease may be achievable with transplantation. ${ }^{218-220}$

- Familial amyloid polyneuropathy should continue to be evaluated as an indication for transplantation with particular regard to the influence of genotypic and phenotypic variants and stage of disease on outcome. (Recommendation grade C.)

Adult polycystic liver and kidney disease-Renal replacement therapy which has modified the natural history of this disorder has allowed increasing awareness of the complications arising from the liver involvement. Symptomatic relief may be obtained from various palliative operations such as aspiration, partial hepatectomy, and defenestration. The decision to transplant is based on the severity of symptoms (pain, abdominal distension, and dyspnoea) produced by the enlarging cysts. ${ }^{221}$ A synchronous kidney transplant should be considered if the patient is already dependent on dialysis, or has a rate of decline of creatinine clearance which suggests that dialysis would be required within two years. Functional hepatic venous outflow obstruction or discomfort unrelieved by palliative measures should precipitate assessment for transplantation.

Caroli's syndrome-This congenital condition characterised by cystic dilatation of intrahepatic bile ducts is variably associated with congenital hepatic fibrosis. The pathological changes may be generalised throughout the liver or localised to one lobe. Cases are selected for transplantation on the basis of recurrent episodes of cholangitis with impairment of quality of life and repeated hospitalisation. Active sepsis must be controlled at the time of transplantation.

Multiple adenomatosis-Multiple adenomatosis with involvement of the entire liver is a rare occurrence and if symptomatic, given the potential for malignant change, is an indication for liver transplantation.

Rare metabolic disorders-Several rare liver derived metabolic defects are corrected by liver replacement. Familial homozygous hypercholesterolaemia, erythropoietic protoporphyia, hyperoxaluria, haemophilia, and protein $\mathrm{C}$ 
deficiency are examples where transplantation has been performed in adolescents and adults to arrest systemic/extrahepatic disease progression.

Multi-organ transplants-Liver and kidney transplantation is considered a management option in hyperoxaluria (oxalosis type 1), adult polycystic liver and kidney disease, familial amyloid polyneuropathy, and other miscellaneous conditions. Anecdotally, a glomerular filtration rate below $25 \mathrm{ml} /$ minute at the time of isolated liver transplantation is likely to provoke end stage renal failure in the first postoperative year. The outcome of this combined procedure is good with some immunoprotection of the renal graft possibly present.

The rarer combination of heart and/or lung and liver transplantation has been successfully performed in cirrhotic patients with severe pulmonary hypertension, cystic fibrosis, and genetic haemochromatosis and is now being considered for cases of hereditary amyloidosis. Over $70 \%$ survival at three years has been reported in transplanted young patients with cystic fibrosis with end stage respiratory failure complicated by related cirrhosis. ${ }^{222} 223$ The level of respiratory reserve and microbiological hazard acceptable for isolated liver transplantation has however exceeded clinical expectation.

\subsubsection{Contraindications}

The list of conditions which represent absolute contraindications to transplantation is diminishing (box 1). Extrahepatic malignancy, advanced AIDS, or severe cardiorespiratory disease remain absolute contraindications. HIV positivity per se can no longer be regarded as an absolute contraindication in view of encouraging data on combination antiretroviral therapy. Severe pulmonary hypertension (mean pressure $>35 \mathrm{~mm} \mathrm{Hg}$ ) and complete portal venous system thrombosis (confirmed by selective hepatic angiography) are other liver related disorders in which a transplant is not possible.

Isolated portal vein thrombosis can now be circumvented either by jump grafts or after thromboendovenectomy. ${ }^{224}$ Significant sepsis outside the biliary tree is a relative contraindication to transplantation and must be treated effectively.

\subsubsection{Rehabilitation}

Despite the potential pitfalls awaiting liver recipients at all stages after transplantation, as outlined earlier, the present populations are experiencing improved quality of life and often a return to employment. ${ }^{225} 226$ Reproductive capability is restored after transplantation and the risks of pregnancy are generally small. ${ }^{227}$ The prevalence of psychiatric morbidity in liver transplant recipients is comparable with the general population. ${ }^{228} 229$ In a few patients, however, where established medical complaints persist (e.g. osteoporosis) or where family and marital breakdown accompanied their illness, full rehabilitation is not possible.

\section{Appendix I}

PROGNOSTIC MODELS IN PRIMARY SCLEROSING CHOLANGITIS

Mayo model

$0.535 \log _{\mathrm{e}}$ serum bilirubin $(\mathrm{mg} / \mathrm{dl})$

+0.486 histological stage

+0.041 age (years)

+0.705 if splenomegaly present

PROGNOSTIC MODELS IN PRIMARY BILIARY

CIRRHOSIS

European model

$2.51 \times \log _{\mathrm{e}}$ serum bilirubin $(\mu \mathrm{mol} / \mathrm{l})$

$+(($ age exp $($ age $[\mathrm{yrs}]-20) / 10)$

+0.88 if cirrhosis present -0.05 serum albumin $(\mathrm{g} / \mathrm{l})$

+0.68 if central cholestasis present

+0.52 if not treated with azathioprine

Mayo model

$0.871 \log _{\text {e }}$ serum bilirubin $(\mathrm{mg} / \mathrm{dl})-2.53$ $\log _{\mathrm{e}}$ albumin (g/dl)

+0.039 age (years)

$+2.38 \log _{\mathrm{e}}$ prothrombin time (seconds)

+0.859 if peripheral oedema present

Christensen model

$2.53 \mathrm{log}$ serum bilirubin $(\mu \mathrm{mol} / \mathrm{l})-1.53$

+1.39 if ascites present -0.085 serum albumin $(\mathrm{g} / \mathrm{l})-34.3$

+0.4 age (years) -55

+0.065 if gastrointestinal bleeding present UNOS SCALE

I Full-time employment

II Part-time employment

III Housebound

IV Hospitalised

$\mathrm{V}$ Intensive care unit

VI Intentsive care unit, life support

\subsection{References}

1 Eccles M, Clapp Z, Grimshaw J, et al. North of England evidence based guidelines development project: methods of guideline development. BMF 1996;312:760-2.

2 Office for National Statistics. Mortality Statistics 1993 and 1994 Cause. England and Wales. Series DH2 No. 31. London: Office for National Statistics.

3 London: Office for National Statistics. certification for alcoholic liver disease. Br Med $\mathcal{F}$ Clin Res Ed certification for

4 Davies MH, Langman MJ, Elias E, et al. Liver disease in a district hospital remote from a transplant centre: a study of admissions and deaths. Gut 1992;33:1397-9.

5 Metcalf J, James O. The geoepidemiology of primary biliary cirrhosis. Semin Liver Dis 1997;17:13-22.

6 United Kingdom Transplant Support Service Authority. Transplant Activity 1997. Seventh annual report of the Special Health Authority, 1997.

7 McLindon JP, Paver WK, Babbs C, et al. Hepatitis C related chronic liver disease among asymptomatic blood donors in the north west of England. F Infect 1995;30:253-9.

8 Mutimer DJ, Harrison RF, O'Donnell KB, et al. Hepatitis C infection in the asymptomatic British blood donor. F Viral Hepatol 1995:2:47-53.

9 Wreghitt TG, Gray JJ, Allain JP, et al. Transmission of hepatitis C virus by organ transplantation in the United titis C virus by organ transplantation
Kingdom. F Hepatol 1994;20:768-72.

10 Durante AJ, Heptonstall J. How many people in England and Wales risk infection from injecting drug use? Commun Dis Rep CDR Rev 1995;5:R40-4.

11 Majid A, Homes R, Desselberger H, et al. Molecular epidemiology of hepatitis $C$ virus infection among intravenous drug users in rural communities. $\mathcal{F}$ Med Virol 1995;45:4851.

12 Alter MJ. Epidemiology of hepatitis C. Hepatology 1997;26: $625-55$

13 Metcalf JV, Bhopal RS, Gray J, et al. Incidence and prevalence of primary biliary cirrhosis in the city of Newcastle upon Tyne, England. Int $\mathcal{F}$ Epidemiol 1997;26: $830-6$.

14 Hodges JR, Millward-Sadler GH, Wright R. Chronic active hepatitis: the spectrum of disease. Lancet 1982;i:550-2.

15 O'Grady JG, Alexander GJ, Hayllar KM, et al. Early indicators of prognosis in fulminant hepatic failure. Gastroenterology 1989;97:439-45. 
16 Gunnell D, Hawton K, Murray V, et al. Use of paracetamol for suicide and non-fatal poisoning in the UK and France: are restrictions on availablity

17 Centers for Disease Control. Deaths and hospitalizations from chronic liver disease and cirrhosis: United States, 1980-1989. ҒAMA 1993;269:569-72

18 Alter MJ, Margolis HS, Krawczynski K, et al. The natural history of community-acquired hepatitis C in the United States. The Sentinel Counties Chronic non-A, non-B Hepatitis Study Team. N Engl f Med 1992;327:1899-905.

19 Forbes A, Williams R. Increasing age: an important adverse prognostic factor in hepatitis A virus infection. $\mathcal{F} R$ Coll Prognostic factor in hepatitis A

20 Friis H, Andreasen PB. Drug-induced hepatic injury: an analysis of 1100 cases reported to the Danish committee on adverse drug reactions between 1978 and 1987. F Intern Med 1992;232:133-8.

21 Mitchell I, Wendon J, Williams R. Anti-tuberculous therapy and acute liver failure. Lancet 1995;345:555-6.

22 Gough A, Chapman S, Wagstaff K, et al. Minocycline induced autoimmune hepatitis and systemic lupus erythematosis-like syndrome. BMF 1996;312:169-72.

23 Ellis AJ, Wendon JA, Williams R. Acute liver damage and ecstasy ingestion. Gut 1996;38:454-8.

24 Wysowski DK, Fourcroy JL. Flutamide hepatotoxicity. $f$ Urol 1996;155:209-12.

25 Garcia-Rodriguez LA, Gutthann SS, Walker AM, et al. The role of non-steroidal anti-inflammatory drugs in acute liver injury. BMF 1992;305:865-8.

26 Pereira SP, Williams R. Limits to liver transplantation in the UK. Gut 1998;42:883-5.

27 Belle SH, Beringer KC, Murphy JB, et al. Liver transplantation in the United States: 1988 to 1990 . Clin Transplant 1992;13:13-29.

28 Belle SH, Detre KM. Report from the Pitt-UNOS liver transplant registry. Transplant Proc 1993;25:1137-42.

29 European Liver Transplant Registry. 1992 Update 31/12/ 92.

30 United Kingdom Transplant Support Service Authority. Liver transplant audit 1985-1995, 1997

31 Van Thiel DH. When should a decision to proceeed with transplantation actually be made in cases of fulminant or subfulminant hepatic failure: at admission to hospital or when a donor organ is made available? $\mathcal{F}$ Hepatol 1993;17 $1-2$.

32 Christensen E, Bremmelgaard A, Bahnsen M, et al. Prediction of fatality in fulminant hepatic failure. Scand $\mathcal{F}$ Gastroenterol 1984;19:90-6.

33 Bernuau J, Goudeau A, Poynard T, et al. Multivariate analysis of prognostic factors in fulminant hepatitis B. Hepatology 1986;6:648-51.

34 Gimson AES, O'Grady J, Ede RJ, et al. Late onset-hepatic failure; clinical, serological and histological features. Hepatology 1986;6:288-94.

35 O'Grady JG, Schalm S, Williams R. Acute liver failure: redefining the syndromes. Lancet 1993;342:273-5.

36 Trey C. The fulminant hepatic failure surveillance study: brief review of the effects of presumed aetiology and age on survival. CMAf 1972;106:525-6.

37 Rakela J. Etiology and prognosis in fulminant hepatitis: acute hepatic failure study group [abstract]. Gastroenterology 1979;77:A33.

38 Karvountzis GG, Redeker AG. Relation of alphafetoprotein in acute hepatitis to severity and prognosis. Ann Intern Med 1974;80:156-60.

39 Tygstrup N, Ranek L. Assessment of prognosis in fulminant hepatic failure. Semin Liver Dis 1986;6:129-37.

40 Scaiola A, MacMathuna P, Langley P, et al. Determination of the ketone-body ratio in fulminant hepatic failure. Hepatogastroenterology 1990;37:413-16.

41 Saibara T, Onishi S, Sone J, et al. Arterial ketone body ratio as a possible indicator for liver transplantation in fulminan hepatic failure. Transplantation 1991;51:782-6.

42 Harrison P, O'Grady J, Alexander G, et al. Serial prothrombin time: a prognostic indicator in paracetamolinduced fulminant hepatic failure. BMf 1990;301:964-6.

43 Bernuau J, Samuel D, Durand F, et al. Criteria for emergency liver transplantation in patients with acute viral hepatitis and factor V below $50 \%$ of normal: a prospective study [abstract]. Hepatology 1991;14:49A.

44 Johnson PJ, McFarlane IG (convenors on behalf of the panel). Special Article: International Autoimmune Hepatitis Group. Hepatology 1993;18:998-1005.

45 Keating JJ, Johnson RD, Johnson PJ, et al. Clinical course of cirrhosis in young adults and therapeutic potential of liver cirrhosis in young adults and therapeutic
transplantation. Gut 1985;26:1359-63.

46 Czaja AJ, Davis GL, Ludwig J, et al. Autoimmune features as determinanants of prognosis in steroid-treated chronic active hepatitis of uncertain aetiology. Gastroenterology 1983;85:713-17.

47 Keating JJ, O'Brien CJ, Stellon AJ, et al. Influence of aetiology, clinical and histological features on survival in chronic active hepatitis. An analysis of 204 patients. $Q \mathcal{F}$ Med 1987;62:59-66.

48 Czaja AJ, Hay JE, Rakela J. Clinical features and prognostic implications of severe cortico-steroid-treated cryptogenic chronic active hepatitis. Mayo Clin Proc 1990;65:25-30.

49 Hegarty JE, Nouri-Aria KT, Portmann B, et al. Relapse following treatment withdrawal in patients with autoimmune chronic active hepatitis. Hepatology 1983;3:685-9.

50 Johnson P. Treatment of autoimmune hepatitis. Gut 1997;41:3-4
51 Okolicsanyi L, Fabris L, Viaggi S, et al. Primary sclerosing cholangitis: clinical presentation, natural history and prognostic variables: an Italian multicentre study. The Italian PSC Study Group. Eur f Gastroenterol Hepatol 1996;8:68591.

52 Broome U, Olsson R, Loof L, et al. Natural history and rognostic factors in 305 Swedish patients with primary sclerosing cholangitis. Gut 1996;38:610-15.

53 Farrant JM, Hayllar K, Wilkinson ML, et al. Natural history and prognostic variables in primary sclerosing cholangitis. Gastroenterology 1991;100:1710-17.

54 Dickson ER, Murtaugh PA, Wiesner RH, et al. Primary sclerosing cholangitis: refinement and validation of survival models. Gastroenterology 1992;103:1893-901.

55 Shetty K, Rybicki L, Carey WD. The Child-Pugh classification as a prognostic indicator for survival in primary sclerosing cholangitis. Hepatology 1997;25:104953

56 Brentnall TA, Hagitt RC, Rabinovitch PS, et al. Risk and natural history of colonic neoplasia in patients with primary sclerosing cholangitis and ulcerative colitis. Gastroenterology 1996;110:331-8.

57 Neuberger J, Farrant M. Chapter 5. In: Williams R, Portmann B, Tan KC, eds. The practice of liver transplantation. Edinburgh: Churchill Livingstone, 1995.

58 Nishiguchi S, Kuroki T, Yabusako T, et al. Detection of hepatitis $C$ virus antibodies and hepatitis $C$ virus RNA in patients with alcoholic liver disease. Hepatology 1991;14: 985-9.

59 Pares A, Barrera JM, Caballeria J, et al. Hepatitis C virus antibodies in chronic alcoholic patients: association with severity of liver injury. Hepatology 1990;12:1295-9.

60 Esteban JI, Esteban R, Viladomiu L, et al. Hepatitis C antibodies among risk groups in Spain. Lancet 1989;ii:294-7.

61 Office for National Statistics. Social trends. London: The Statistical Office, 1997;27:132.

62 Leevy CM. Cirrhosis in alcoholics. Med Clin North Am 1968;52:1445-55.

63 Bouchier IA, Hislop WS, Prescott RJ. A prospective study of alcoholic liver disease and mortality. $\mathcal{F}$ Hepatol 1992;16: 290-7.

64 Powell WJ, Klatskin G. Duration of survival in patients with Laennec's cirrhosis. Am f Med 1978;94:695-716.

65 Maddrey WC, Boitnott JK, Bedine MS, et al. Corticosteroid therapy of alcoholic hepatitis. Gastroenterology 1978;75 193-9.

66 Mendenhall CL. Alcoholic hepatitis. Clin Gastroenterol 1981;10:417-41.

67 Maddrey WC. Alcoholic hepatitis: clinicopathologic features and therapy. Semin Liver Dis 1989;8:91-102.

68 Ramond MJ, Poynard T, Rueff B, et al. A randomized trial of prednisolone in patients with severe alcoholic hepatitis. $N$ Engl f Med 1992;326:507-12.

69 Gines P, Quintero E, Arroyo V, et al. Compensated cirrhosis: natural history and prognostic factors. Hepatology 1987;7: $122-8$.

70 D'Amico G, Morabito A, Pagliaro L, et al. Survival and prognostic indicators in compensated and decompensated cirrhosis. Dig Dis Sci 1986;31:468-75.

71 Tito L, Rimola A, Gines P, et al. Recurrence of spontaneous bacterial peritonitis in cirrhosis: frequency and predictive factors. Hepatology 1988;8:27-31.

72 Orrego H, Israel Y, Blake JE, et al. Assessment of prognostic factors in alcoholic liver disease: towards a global quantitative expression of severity. Hepatology 1983;3:896-905.

73 Pugh RNH, Murray-Lyon IM, Dawson JL. Transection of the oesophagus for bleeding oesophageal varices. Br F Surg 1973;60:646-9.

74 Gluud C, Henriksen J H, Nielsen G, et al. Prognostic indicators in alcoholic cirrhotic men. Hepatology $1988 ; 8$ $222-7$.

75 de-Franchis R, Meucci G, Vecchi M, et al. The natural history of asymptomatic hepatitis B surface antigen carriers. Arch Intern Med 1993;118:191-4.

76 Sakuma K, Saitoh N, Kasai M, et al. Relative risks of death due to liver disease among Japanese male adults having various statuses for hepatitis $\mathrm{B}$ s and e antigen/antibody in serum: a prospective study. Hepatology 1988;8:1642-6.

77 Fattovich G, Brollo L, Giustina G, et al. Natural history and progno $294-8$.

78 Tsai SL, Yang PM, Lai MY, et al. Natural history of hepatitis B surface antigen-positive cirrhosis in Taiwan: a clinicopathological study. $f$ Gastroenterol Hepatol 1998;3: 583-92.

79 Realdi G, Fattovich G, Hadziyannis SJ, et al. Survival and prognostic factors in 366 patients with compensated cirrhosis type B: a multicentre study.

80 Zarski JP, Seigneurin JM. Genetic variability of hepatitis B virus: relationship with pathogenicity. Gastroenterol Clin Biol 1991;15:277-9.

81 Bonino F. The importance of hepatitis B viral DNA in serum and liver. F Hepatol 1986;3:136-41.

82 Rizzetto M, Verme G, Gerin JL, et al. Hepatitis delta virus disease. Prog Liver Dis 1986;8:417-31.

83 Poynard T, Bedossa P, Opolon P. Natural history of liver fibrosis progression in patients with chronic hepatitis C. The OBSVIRC, METAVIR, CII

84 Roudot-Thoraval F, Bastie A, Pawlotsky JM, et al. Epidemiological factors affecting the severity of hepatitis $C$
virus-related liver disease: a French survey of 6,664 patients. Hepatology 1997;26:485-90. 
85 Fattovich G, Giustina G, Degos F, et al. Morbidity and mortality in compensated cirrhosis type C: a retrospective follow-up

86 Zeusem S, Franke A, Lee JH, et al. Phylogenetic analysis of hepatitis $\mathrm{C}$ virus isolates and their correlation to viremia, liver function tests, and histology. Hepatology 1996;24 1003-9.

87 Ohno T, Lau JYN. The 'gold-standard' accuracy, and the current concepts: Hepatitis C virus genotype and viraemia. Hepatology 1996;24:1312-15.

88 Okuda K. Hepatocellular carcinoma: recent progress. Hepatology 1992;15:948-63.

89 Haydon GH, Jarvis LM, Simmonds P, et al. Association between chronic hepatitis C infection and hepatocellular carcinoma in a Scottish population. Gut 1997;40:128-32.

90 Cottone M, Virdone R, Fusco G, et al. Asymptomatic hepatocellular carcinoma in Child's A cirrhosis. A comparison of natural history and surgical treatment. Gastroenterology 1989;96:1566-71.

91 Sheu JC, Sung JL, Chen DS, et al. Growth rate of asymptomatic hepatocellular carcinoma and its clinical implications. Gastroenterology 1985;89:259-66.

92 Stuart KE, Anand AJ, Jenkins RL. Hepatocellular carcinoma in the United States. Prognostic features, treatment outcome, and survival. Cancer 1996;77:2217-22

93 Craig JR, Peters RL, Edmondson HA, et al. Fibrolamella carcinoma of the liver: a tumour of adolescents and young
adults with distinctive clinico-pathologic features. Cancer adults with distinc

94 Berman MA, Burnham JA, Sheahan DG. Fibrolamellar carcinoma of the liver: an immunohistochemical study of nineteen cases and a review of the literature. Hum Patho 1988;19:784-94.

95 Blumgart LH, Benjamin IS. Cancer of the bile ducts. In Surgery of the liver and biliary tract. Edinburgh: Churchil Livingstone, 1994:967.

96 Nordback IH, Pitt HA, Coleman J, et al. Unresectable hilar cholangiocarcinoma: percutaneous versus operative palliacholangiocarcinoma: percutaneous

97 Yeo CJ, Pitt HA, Cameron JL. Cholangiocarcinoma. Surg Clin North Am 1990;70:1429.

98 Flickinger JC, Epstein AH, Iwatsuki S, et al. Radiation therapy for primary carcinoma of the extrahepatic biliary system. An analysis of 63 cases. Cancer 1991;68:289-94.

99 Buskirk SJ, Gunderson LL, Schild SE, et al. Analysis of failure after curative irradiation of extrahepatic bile duct duct carcinoma. Ann Surg 1992;215:125-31.

100 Ishak KG, Sesterhenn IA, Goodman MZD, et al. Epithelioid haemangioendothelioma of the liver: a clinicopathologic and follow-up study of 32 cases. Human Pathol 1984;15:839-52.

101 Clements D, Hubscher S, West R, et al. Epithelioid haemangioendothelioma: a case report. 7 Hepatol 1986;2: $441-9$.

102 Valla D, Benhamou JP. Disorders of hepatic veins and venules. In: Oxford textbook of clinical hepatology. Oxford: Oxford University Press, 1991

103 Griffith JF, Mahmoud AE, Cooper S, et al. Radiological intervention in Budd-Chiari syndrome: techniques and outcome in 18 patients. Clin Radiol 1996;51:775-84.

104 McCarthy PM, Van Heerden JO, Adson MA, et al. The Budd-Chiari syndrome. Medical and surgical managment of 30 patients. Arch Surg 1985;120:657-62.

105 Ahn SS, Yellin A, Sheng FC, et al. Selective surgical therapy of the Budd-Chiari syndrome provides superior survivor rates than conservative medical management. $\mathcal{F}$ Vasc Surg 1987;5:28-37.

106 Ochs A, Sellinger M, Haag K, et al. Transjugular intrahepatic portosystemic stent shunt (TIPS) in the treatment of Budd-Chiari syndrome. F Hepatol 1993;18:21725.

107 Klein AS, Cameron JL. Diagnosis and management of the Budd-Chiari syndrome. Am F Surg 1990;160:128-33.

108 Shaked A, Goldstein RM, Klintmalm GB, et al. Portosystemic shunt versus orthotopic liver transplantation for the
Budd-Chiari syndrome. Surg Gynecol Obstet 1992;174: 453-9.

109 Henderson JM, Warren WD, Millikan WJ, et al. Surgical options, hematologic evaluation, and pathologic changes in Budd-Chiari syndrome. Am 7 Surg 1990;159:41-8.

110 Starzl TE, Marchioro TL, von Kaulla K, et al. Homotransplantation of the liver in humans. Surg Gynaecol Obstet 1963;117:659-76.

111 Starzl TE, Groth CG, Brettschneider L, et al. Orthotopic homotransplantation of the human liver. Ann Surg 1968:168:392.

112 Calne RY, Williams R. Liver transplantation in man. I. Observations on technique and organisation in five cases. $B M F$ 1968;iv:535.

113 Evans RW. Organ transplantation and the inevitable debate as to what constitutes a basic health care benefit. Clin Transplant 1993;14:359-91.

114 Roy First M.Transplantation in the Nineties. Transplantation 1992;53:1-11.

115 Steinbrook R. Allocating livers-devising a fair system. $N$ Engl F Med 1997;336:436-8.

116 Benjamin M, Turcotte JG. Ethics, alcoholism, and liver transplantation. In: Lucey MR, Merion RM, Beresford TP, eds. Liver transplantation and the alcoholic patient. eds. Liver transplantation and the alcoholic patient.

117 Starzl TE, Todo S, Gordon R, et al. Liver transplantation in older patients. N Engl f Med 1987;316:484-5.
118 Slapak GI, Saxena R, Portmann B, et al. Graft and systemic disease in long-term survivors of liver transplantation. Hepatology 1997;25:195-202.

119 Dickson ER, Grambsch PM, Fleming TR, et al. Prognosis in primary biliary cirrhosis. Hepatology 1989;10:1-7.

120 Wiesner RH, Grambsch PM, Dickson ER, et al. Primar sclerosing cholangitis: natural history, prognostic factors and survival analysis. Hepatology 1989;10:430-6.

121 Weissberg JI, Andres LL, Smith CI, et al. Survival in chronic hepatitis B. An analysis of 379 patients. Ann Intern Med 1984;101:613-16.

122 Neuberger JM, Gunson BK, Buckels JA, et al. Referral of patients with primary biliary cirrhosis for liver transplantaion. Gut 1990;31:1069-72.

123 Markus BH, Dickson ER, Grambsch PM, et al. Efficacy of liver transplantation in patients with primary biliary cirrhois. N Engl f Med 1989;320:1709-13.

124 Cooper J, Wiesner RH, Dickson ER, et al. Severity of disease predicts the cost of liver transplantation [abstract]. Hepatology 1990;12:A838.

125 Wiesner RH, Porayko MK, Dickson ER, et al. Selection and timing of liver transplantation in primary biliary cirrhosis and primary sclerosing cholangitis. Hepatology 1992;16:1290-9.

126 Ricci P, Therneau TM, Malinchoc M, et al. A prognostic model for the outcome of liver transplantation in patients with cholestatic liver disease. Hepatology 1997;25: $672-7$.

127 Baliga P, Merion RM, Turcotte JG, et al. Preoperative risk factor assessment in liver transplantation. Surgery 1992; 112:704-10

127a Wiesner RH, Porayako MK, Dickson R, et al. Selection and timing of liver transplantation in primary biliary cirrhosis and primary sclerosing cholangitis. Hepatology 1992;16:1290-9.

127b Neuberger JM, Gunson BK, Buckels JCA, et al. Referral of patients with primary biliary cirrhosis. Gut 1990;31: 1069-72.

128 Zauner CA, Apsner RC, Kranz A, et al. Outcome prediction for patients with cirrhosis of the liver in a medical ICU: a comparison of the APACHE scores and liver-specific scoring systems. Intensive Care Med 1996;22: 559-63.

129 Zimmerman JE, Wagner DP, Seneff MG, et al. Intensive care unit admissions with cirrhosis: risk-stratifying patient groups and predicting individual survival. Hepatology 1996; 23:1393-40.

130 Shaw BJ, Wood RP, Stratta RJ, et al. Stratifying the causes of death in liver transplant recipients. An approach to improving survival. Arch Surg 1989 124:895-900.

131 McCullough AJ, Tavill AS. Disordered energy and protein metabolism in liver disease. Semin Liver Dis 1991;11:26577.

132 Harrison J, McKiernan J, Neuberger JM. A prospective study on the effect of recipient nutritional status outcom in liver transplantation. Transplant Int 1997;10:369-74.

133 Makin AJ, Wendon J, Williams R. A 7-year experience of severe acetaminophen-induced hepatotoxicity (19871993). Gastroenterology 1995;109:1907-16.

134 O’Grady JG, Wendon J, Tan KC, et al. Liver transplantation after paracetamol overdose. BMF 1991;303:221-3.

135 Pauwels A, Mostefa KN, Florent C, et al. Emergency liver transplantation for acute liver failure. Evaluation of London and Clichy criteria. F Hepatol 1993;17:124-7.

136 Mutimer DJ, Ayres RC, Neuberger JM, et al. Serious paracetamol poisoning and the results of liver transplantation. Gut 1994;35:809-14.

137 Devlin J, Wendon J, Heaton N, et al. Pretransplantation clinical status and outcome of emergency transplantation for acute liver failure. Hepatology 1995;21:1018-24.

138 European Liver Transplant Registry. 1997 Annual report. Paris: European Liver Transplant Registry.

139 Schilsky ML, Scheinberg IH, Sternlieb I. Liver transplantation for Wilson disease: indications and outcome. Hepatology 1994;19:583-7.

140 Seaberg EC, Belle SH, Beringer KC, et al. Long-term patient and retransplantation-free survival by selected recipient and donor characteristics: an update from the Pitt-UNOS liver transplant registry. Clin Transplant 1997; 18:15-28

141 Bonsel GJ, Klompmaker IJ, Van'T Veer F, et al. Use of prognostic models for assessment of value of liver transplantation in primary biliary cirrhosis. Lancet 1990; 335:493-7.

142 Farges O, Malassagne B, Sebagh M, et al. Primary sclerosing cholangitis: liver transplantation or biliary surgery. Surgery 1995;117:146-55.

143 Abu-Elmagd KM, Malinchoc M, Dickson ER, et al. Efficacy of hepatic transplantation in patients with primary sclerosing cholangitis. Surg Gynecol Obstet 1993;177:33544 .

144 Goss JA, Shackleton CR, Farmer DG, et al. Orthotopic liver transplantation for primary sclerosing cholangitis. A 12-year single centre experience. Ann Surg 1997;225:47281

145 Harrison RF, Davies MH, Neuberger JM, et al. Fibrous and obliterative cholangitis in liver allografts: evidence of recurrent primary sclerosing cholangitis? Hepatology 1994; 20:356-61.

146 Sheng R, Campbell WL, Zajko AB, et al. Cholangiographic features of biliary strictures after liver transplantation for primary sclerosing cholangitis: evidence of recurrent disease. AfR Am f Roentgenol 1996;166:1109-13. 
147 Knechtle SJ, D’Alessandro AM, Harms BA, et al. Relationships between sclerosing cholangitis, inflammatory bowel disease, and cancer in patients undergoing live transplantation. Surgery 1995;118:615-19.

148 Nashan B, Schlitt HJ, Tusch G, et al. Biliary malignancies in primary sclerosing cholangitis: timing for liver transplantation. Hepatology 1996;25:1105-11.

149 Sanchez-Urdazpal L, Czaja AJ, van Hoek B, et al. Prognostic features and role of liver transplantation in severe corticosteroid-treated autoimmune chronic active hepatitis. Hepatology 1991;15:215-21.

150 Grant BF, Dufour MC, Harford TC. Epidemiology of alcoholic liver disease. Semin Liver Dis 1988;8:12-25.

151 Theodossi A, Eddleston AL, Williams R. Controlled trial of methylprednisolone therapy in severe acute alcoholic hepatitis. Gut 1982;23:75-9.

152 Shakil AO, Pinna A, Demetrtis J, et al. Survival and quality of life after liver transplantation for acute alcoholic hepatiof life after liver transplantation for acute alcoholic
tis. Liver Transplantation and Surgery 1997;3:240-4.

153 Beresford TP. Psychiatric assessment of alcoholic liver transplant candidates. In: Lucey MR, Merion RM, Beresford TP, eds. Liver transplantation and the alcoholic patient. Cambridge: Cambridge University Press, 1994.

154 Vaillant GE, Clark W, Cyrus C, et al. Prospective study of alcoholism treatment. Eight-year follow-up. $\mathrm{Am} \mathcal{F} \mathrm{Med}$ 75:455-63.

155 Strauss R, Bacon SD. Alcoholism and social stability. $Q \mathcal{F}$ Study Alc 1951;12:231-60.

156 Foster PF, Fabrega F, Karademir S, et al. Prediction of abstinence from ethanol in alcoholic recipients following liver transplantation. Hepatology 1997;25:1469-77.

157 Harper CG, Krill JJ. Neuropathology of alcoholism. Alcohol Alcohol 1990;25:207-16.

158 Arria AM, Tarter SE, Starzl TE, et al. Improvement in cognitive functioning of alcoholics following orthotopic liver nitive functioning of alcoholics following orthotopic

159 Estruch R, Fernandez-Sola J, Sacanella E, et al. Relationship between cardiomyopathy and liver disease in chronic ship between cardiomyopathy and liver
alcoholism. Hepatology 1995;22:532-8.

160 Dreiling DA, Koller M. The natural history of alcoholic pancreatitis: update 1986. Mt Sinai f Med 1985;52:340-2.

161 O'Keefe SJ, El ZA, Carraher TE, et al. Malnutrition and immuno-incompetence in patients with liver disease. Lancet 1980;20:615-17.

162 Mendenhall CL, Anderson S, Garcia-Pont P, et al. Short-term and long-term survival in patients with alcoholic hepatitis treated with oxandrolone and prednisolone. N Eng f Med 1984;311:1464-70.

163 Poynard T, Barthelemy P, Fratte S, et al. Evaluation and efficacy of liver transplantation in alcoholic cirrhosis by a case-control study and simulated controls. Lancet 1994; 344:502-7.

164 Lucey MR, Carr K, Beresford TP, et al. Alcohol use after liver transplantation in alcoholics: a clinical cohort
follow-up study. Hepatology 1997;25:1223-7.

165 Vaillant GE. The natural history of alcoholism and its relationship to liver transplantation. Liver Transplantation and Surgery 1997;3:304-10

166 Naumann U, Protzer-Knolle U, Berg T, et al. A pretransplant infection with precore mutants of hepatitis $\mathrm{B}$ virus does not influence the outcome of orthotopic liver transplantation in patients on high dose anti-hepatitis B virus surface antigen immunoprophylaxis. Hepatology 1997;26:478-84.

167 O'Grady JG, Smith HM, Davies SE, et al. Hepatitis B virus reinfection after orthotopic liver transplantation. Serologi$\mathrm{cal}$ and clinical implications. F Hepatol 1992;14:104-11.

168 Samuel D, Muller R, Alexander G, et al. Liver transplantation in HBsAg positive patients; an European experience tion in HBsAg positive patients; an Europea

169 Samuel D, Bismuth A, Mathieu D, et al. Passive immunoprophylaxis after liver transplantation in HBsAg-positive patients. Lancet 1991:337:813-15.

170 Devlin J, Smith HM, O'Grady J, et al. Impact of immunoprophylaxis and patient selection on outcome of transplantation for HBsAg-positive liver recipients. $\mathcal{f}$ Hepato 1994;21:204-10.

171 Grellier L, Mutimer D, Ahmend M, et al. Lamivudine prophylaxis against reinfection in liver transplantation for hepatitis B cirrhosis. Lancet 1996;348:1212-15.

172 Gane EJ, Portmann B, Naoumov NV, et al. Long-term outcome of hepatitis $\mathrm{C}$ infection after liver transplantation. N Engl f Med 1996;334:815-20.

173 Figueras J, Jaurrieta E, Valls C, et al. Survival after liver transplantation in cirrhotic patients with and without hepatocellular carcinoma: a comparative study. Hepatology 1997;25:1485-9.

174 Lerut JP, Laterre PF, Lavenne-Pardonge E, et al. Liver transplantation and haemophilia A. F Hepatol 1995;22:583-5.

175 Gordon FH, Mistry PK, Sabin CA. Outcome of orthotopic liver transplantation in patients with haemophilia. Gut 1998;42:744-9.

176 Williams R, Smith M, Shilkin KB, et al. Liver transplantation in man: the frequency of rejection and recurrence of malignancy based on an analysis of 26 cases. Gastroenterology 1973;64:1026-48.

177 Penn I. Hepatic transplantation for primary and metastatic cancers of the liver. Surgery 1991;110:726-34.

178 Iwatsuki S, Gordon RD, Shaw BJ, et al. Role of liver trans-

plantation in cancer therapy. Ann Surg 1985;202:401-7.
179 Ringe B, Pichlmayr R, Wittekind C, et al. Surgical treatment of hepatocellular carcinoma: experience with treatment of hepatocellular carcinoma: experience with
liver resection and transplantation in 198 patients. World $\mathcal{f}$ liver resection and transp
Surg 1991;15:270-85.
180 Bismuth $\mathrm{H}$, Chiche L, Adam R, et al. Liver resection versus transplantation for hepatocellular carcinoma in cirrhotic patients. Ann Surg 1993;218:145-51.

181 Gozzetti G, Mazziotti A, Grazi GL, et al. Surgical experience with 168 primary liver cell carcinomas treated with hepatic resection. F Surg Oncol Suppl 1993;3:59-61. 182 Franco D, Capussotti L, Smadja C, et al. Resection of
hepatocellular carcinomas. Results in 72 European patients with cirrhosis. Gastroenterology 1990;98:733-8.

183 Bruix J, Castells A, Bosch J, et al. Surgical resection of hepatocellular carcinoma in cirrhotic patients: prognostic value of preoperative portal pressure. Gastroenterology 1996;111:1018-22.

184 Pichlmayr R, Ringe B, Wittekind C, et al. Liver grafting for malignant liver tumours. Transplant Proc 1989;21:2403-5.

185 Iwatsuki S, Starzl TE, Sheahan DG, et al. Hepatic resection versus transplantation for hepatocellular carcinoma. Ann Surg 1991;214:221-8.

186 Yokoyama I, Todo S, Iwatsuki S, et al. Liver transplantation in the treatment of primary liver cancer. Hepatogastroenterology 1990;37:188-93.

187 Gores GJ. Liver transplantation for malignant disease. Gastroenterol Clin North Am 1993;22:285-99.

188 Steinherz L, Steinherz P. Delayed cardiac toxicity from anthracycline therapy. Pediatrician 1991;18:49-52.

189 Carr BI, Iwatsuki S, Starzl TE, et al. Regional cancer chemotherapy for advanced stage hepatocellular carcinoma. F Surg Oncol Suppl 1993;3:100-3.

190 Stone MJ, Klintmalm GBG, Polter D, et al. Neoadjuvant chemotherapy and liver transplantation for hepatocellular carcinoma: a pilot study of 20 patients. Gastroenterology 1993;104:196-202.

191 Bismuth H, Morino M, Sherlock D, et al. Primary reatment of hepatocellular carcinoma by arterial chemoembolisation. Am f Surg 1992;163:387-94.

192 Groupe d'Etude et de Traitment du Carinome Hepatocellulaire. A comparison of lipiodol chemoembolization and conservative management for unresectable hepatocellular conservative management for unresectable $N$ Engl f Med 1995;332:1256-61.

193 Livraghi T, Lazzaroni S, Meloni F, et al. Intralesional ethanol in the treatment of unresectable liver cancer. World $\mathcal{F}$ Surg 1995;19:801-6.

194 CLIP group. Tamoxifen in treatment of hepatocellular carcinoma: a randomised controlled trial. Lancet 1988;352: 17-20.

195 Castells A, Bruix J, Bru C, et al. Treatment of hepatocellular carcinoma with tamoxifen: a double-blind placebocontrolled trial in 120 patients. Gasteroenterology 1995;109: 917-22.

196 McPeake JR, O'Grady J G, Zaman S, et al. Liver transplantation for primary hepatocellular carcinoma: tumor size and number determines outcome. F Hepatol 1993;18:22634 .

197 Ismail T, Angrisani L, Gunson B K, et al. Primary hepatic malignancy: the role of liver transplantation. Br f Surg 1990;77:983-7.

198 O’Grady JG, Polson RJ, Rolles K, et al. Liver transplantation for malignant disease. Results in 93 consecutive patients. Ann Surg 1988;207:373-9.

199 Pichlmayr R. Is there a place for liver grafting for malignancy? Transplant Proc 1989;20:478-82.

200 Alessiani M, Tzakis A, Todo S, et al. Assessment of five-year experience with abdominal organ cluster transplantation. $\mathcal{F}$ Am Coll Surg 1995;180:1-9.

201 Washburn WK, Lewis WD, Jenkins RL. Aggressive surgical resection for cholangiocarcinoma. Arch Surg 1995; 130:270-6.

202 Klempanauer J, Ridder GJ, Werner M, et al. What constitutes long-term survival for hilar cholangiocarcinoma? Cancer 1997;79:26-34.

203 Marino IR, Todo S, Tzakis AG, et al. Treatment of hepatic epithelioid hemangioendothelioma with liver transplantation. Cancer 1988;62:2079-84.

204 Routley D, Ramage JK, McPeake J, et al. Orthotopic liver transplantation in the treatment of metastatic neuroendocrine tumours of the liver. Liver Transplantation and Surgery 1995;1:118-21.

205 Dousset B, Houssin D, Soubrane O, et al. Metastatic endocrine tumours: is there a place for liver transplantation? Liver Transplantation and Surgery 1995;1:111-17.

206 Makowka L, Tzakis AG, Mazzaferro V, et al. Transplantation of the liver for metastatic endocrine tumors of the intestine and pancreas. Surg Gynaecol Obstet 1989;175: 299-305.

207 Lang H, Oldhafer KJ, Weimann A, et al. Liver transplantation for metastatic neuroendocrine tumors. Ann Surg 1997; 225:347-54.

208 Le-Treut YP, Delpero JR, Dousset B, et al. Results of liver transplantation in the treatment of metastatic neuroendocrine tumours. A 31-case French multicentric study. Ann Surg 1997;225:355-64.

209 Nonami T, Yokoyama I, Iwatsuki S, et al. The incidence of portal vein thrombosis at liver transplantation. Hepatology 1992;16:1195-8.

210 Campbell D J, Rolles K, Jamieson N, et al. Hepatic transplantation with perioperative and long term anticoagulation as treatment for Budd-Chiari syndrome. Medical and surgical management of 30 patients. Surg Gynecol Obstet 1988;166:511-18.

211 Thompson NP, Miller AD, Hamilton G, et al. Emergency rescue hepatic transplantation following shunt surgery for $835-7$. 
212 Ringe B, Lang H, Oldhafer KJ, et al. Which is the best surgery for Budd-Chiari syndrome: venous decompression or liver transplar

patients. Hepatology 1995;21:1337-44.
213 Hemming AW, Langer B, Greig P, et al. Treatment of Budd-Chiari syndrome with portosystemic shunt or liver transplantation. Am f Surg 1996;171:176-80.

214 Lombard M, Mieli-Vergani G. Chapter 9. In: Williams R, Portmann B, Tan KC, eds. The practice of liver transplantation. Edinburgh: Churchill Livingstone, 1995.

215 Powell LW. Does transplantation of the liver cure genetic haemochromatosis? F Hepatol 1992;16:259-61.

216 Tung BY, Tabasco-Minguillan J, Bacon BR, et al. Long-term follow-up after liver transplantation for hereditary haemochromatosis [abstract]. Hepatology 1997;26:860A.

217 Suhr OB, Wiklund U, Eleborg L, et al. Impact of autonomic neuropathy on circulatory instability during liver transplantation for familial amyloidotic polyneuropathy. Transplantation 1997;63:675-9.

218 Holmgren G, Ericzon BG, Groth GG, et al. Clinical improvement and amyloid regression after liver transplantation in hereditary transthyretin amyloidosis. Lancet 1993 . 341:1113-16.

219 Dubrey AW, Davidoff R, Skinner M, et al. Progression of ventricular wall thickening after liver transplantation for familial amyloidosis. Transplantation 1997;64:74-80.

220 Pomfret EA, Lewis WD, Jenkins RL, et al. Effect of orthotopic liver transplantation on the progression of familial amy-
loidotic polyneuropathy. Transplantation 1998;65:918-25.
221 Starzl TE, Reyes J, Tzakis A, et al. Liver transplantation for polycystic liver disease. Arch Surg 1990;125:575-7.

222 Couteil JPA, Soubrane O, Houssin DP, et al. Combined heart-lung-liver, double lung-liver, and isolated liver transplantation for cystic fibrosis in children. Transplant Int 1997;10:33-9.

223 Dennis CM, McNeil KD, Dunnning J, et al. Heart-lungliver transplantation. If Heart Lung Transplant 1996;15: $536-8$

224 Seu P, Shackleton CR, Shaked A, et al. Improved results of liver transplantation in patients with portal vein thrombosis. Arch Surg 1996;131:840-4.

225 Lowe D, O'Grady JG, McEwan J, et al. Quality of life following liver transplantation: a preliminary report. $\mathcal{F} R$ Coll Physicians Lond 1990;24:43-6.

226 Tarter RE, Erb S, Biller PA, et al. The quality of life following liver transplantation: a preliminary report. Gastroenterol Clin North Am 1988;17:207-17.

227 Mass K, Quint EH, Punch MR, et al. Gynecological and reproductive function after liver transplantation. Transplantation 1996;62:476-9.

228 Collis I, Burroughs A, Rolles K, et al. Psychiatric and social outcome of liver transplantation. Br f Psychiatry 1995;166: $521-4$.

229 Commander M, Neuberger J, Dean C. Psychiatric and social consequences of liver transplantation. Transplantation 1992;53:1038-40 